\title{
Adult Age Differences in the Effects of Processing on Storage in Working Memory: A Meta-Analysis
}

\author{
Agnieszka J. Jaroslawska ${ }^{1} \&$ Stephen Rhodes ${ }^{2}$ \\ ${ }^{1}$ School of Philosophy, Psychology and Language Sciences, The University of Edinburgh, \\ United Kingdom \\ ${ }^{2}$ Department of Psychological Sciences, University of Missouri, Columbia, Missouri
}

In press at Psychology 83 Aging (Apr 2019) () 2019, American Psychological Association. This paper is not the copy of record and may not exactly replicate the final, authoritative version of the article. Please do not copy or cite without authors' permission. The final article will be available, upon publication, via its DOI: 10.1037/pag0000358

\begin{abstract}
Normal adult aging is known to be associated with lower performance on tasks assessing the short-term storage of information. However, whether or not there are additional age-related deficits associated with concurrent storage and processing demands within working memory remains unclear. Methodological differences across studies are considered critical factors responsible for the variability in the magnitude of the reported age effects. Here we synthesized comparisons of younger and older adults' performance on tasks measuring storage alone against those combining storage with concurrent processing of information. We also considered the influence of task-related moderator variables. Meta-analysis of effect sizes revealed a small but disproportionate effect of processing on older adults' memory performance. Moderator analysis indicated that equating single task storage performance across age groups (titration) and the nature of the stimulus material were important determinants of memory accuracy. Titration of storage task difficulty was found to lead to smaller, and non-significant, age-differences in dual task costs. These results were corroborated by supplementary Brinley and state-trace analyses. We discuss these findings in relation to the extant literature and current working memory theory as well as possibilities for future research to address the residual heterogeneity in effect sizes. (194 words)
\end{abstract}

Keywords: Working Memory; Dual Task; Aging; Storage and Processing; Meta-analysis

Although there is little consensus on the precise structure and functional capacity of working memory (for reviews see Aben, Stapert, \& Blokland, 2012; Adams, Nguyen, \& Cowan, 2018; Cowan, 2017), it is commonly acknowledged that active processing of 
information separates working memory from simple short-term storage. Indeed, for many, the distinguishing feature of working memory is that it provides a mental workspace capable of storing and processing information in the course of ongoing cognitive activities (e.g., Logie, 2003). Thus, the argument follows that an adequate test of working memory capability must engage both storage and processing mechanisms (see Conway et al., 2005). In tests such as these a sequence of to-be-remembered items can be interspersed with short bursts of processing activity (i.e., complex span task; Daneman \& Carpenter, 1980) or followed by a filled retention interval (i.e., the Brown-Peterson task, J. Brown, 1958; L. Peterson \& Peterson, 1959). The processing tasks used in the literature are varied but typically require a choice between, often two, response options. For example, participants may be asked to verify whether a sentence is true or false (e.g., Daneman \& Carpenter, 1980) or decide if a stimulus appears above or below the center of the screen (e.g., Barrouillet, Bernardin, Portrat, Vergauwe, \& Camos, 2007). Irrespective of the precise nature of the task, successful working memory performance depends not only on one's ability to maintain information for short periods of time, but it is also contingent on overall processing efficiency, and the ability to resist the distraction that the processing activity creates (e.g., Engle, 2002; Engle, Tuholski, Laughlin, \& Conway, 1999; Jarrold \& Towse, 2006).

Numerous studies have shown that performance on tasks requiring the simultaneous storage and processing of information exhibits a sustained decline across the adult lifespan (e.g., Bier, Lecavalier, Malenfant, Peretz, \& Belleville, 2017; Bopp \& Verhaeghen, 2005; Holtzer, Stern, \& Rakitin, 2004). However, after decades of accumulated research, evidence for a disproportionate age effect in processing costs to memory performance remains contradictory and inconclusive. Some studies report an age-related decline in storage+processing performance, which gets larger with increasing cognitive demand (e.g., Mayr \& Kliegl, 1993; Parkinson, Lindholm, \& Urell, 1980; Salthouse, 1990; Wingfield, Stine, Lahar, \& Aberdeen, 1988; Wright, 1981). Other investigations show no age-related increase in the effects of processing on storage, even when task demand was manipulated (e.g., A. D. Baddeley, Logie, Bressi, Sala, \& Spinnler, 1986; Gick, Craik, \& Morris, 1988; Logie, Cocchini, Della Sala, \& Baddeley, 2004; Somberg \& Salthouse, 1982). As a result, the question of whether older participants exhibit a greater level of difficulty in holding information in mind when performing a concurrent processing task remains subject to debate. In the wider literature on dual tasking, methodological differences across studies are often cited as a critical factor responsible for variability in the magnitude of reported age effects (De Ribaupierre \& Ludwig, 2003; Riby, Perfect, \& Stollery, 2004). Therefore, to establish whether contrasting results reflect the specific experimental paradigms adopted, it is crucial to explore possible task-related moderators which may be driving the age-related dual task costs.

Here we synthesized previously published reports assessing age differences in a partic-

Both authors contributed equally. AJ is now at Queen's University Belfast. SR is now at the Rotman Research Institute, Toronto. This work was funded by the Economic and Social Research Council grant 'Working memory across the adult lifespan: An adversarial collaboration' (WoMAAC) ES/N010728/1. The authors thank the WoMAAC team for helpful comments. Data and analysis code are available on the Open Science Framework (https://osf.io/bp359/).

Correspondence concerning this article should be addressed to Agnieszka J. Jaroslawska, School of Psychology, Queen's University Belfast, Belfast, UK, BT7 1NN. E-mail: a.jaroslawska@qub.ac.uk 
ular kind of dual task - the demand to maintain information in mind while performing a concurrent processing task. In the sections that follow, we first outline the debate surrounding age differences in dual task costs and list possible task-related moderating variables, before presenting the advantages of the meta-analytic approach adopted here.

\section{Age Differences in the Effects of Processing on Storage: Contradictory Findings}

Previous research findings regarding age-related costs of processing on storage are equivocal. Early investigations in this area found that older adults experience greater difficulty on storage tasks when tasked with coordination of simultaneous cognitive activities and multiple streams of information. Further, age differences appeared to scale with task complexity: the more complex the task, the larger the age effects (Mayr \& Kliegl, 1993; Parkinson et al., 1980; Salthouse, 1990; Wingfield et al., 1988; Wright, 1981). For example, Verhaeghen, Kliegl, and Mayr (1997) found no age difference in mental arithmetic for a series of simple operations (e.g., $3+1+8-5-2$ ) but a large effect for operations in which parentheses introduced a concurrent storage-plus-processing requirement (e.g., $[8-(1+3)]+$ $(5-2))$. Crucially, the performance gap between younger and older adults is typically greater for tasks assessing working memory, as opposed to short-term storage only (e.g., Bopp \& Verhaeghen, 2005). For instance, Broadbent and Heron (1962) found that age differences in the ability to recall information after a delay were exacerbated when that delay was filled with a processing activity. More recently, in their meta-analysis of the broader literature on aging and dual task costs, Bopp and Verhaeghen (2005) reported that the difference in performance between younger and older adults on complex span tasks was significantly larger than the effect of age on simple span tasks (see also Bier et al., 2017).

Findings such as these led several researchers to emphasize that a primary source of cognitive impairment in storage and processing with advancing age is an impairment of the ability to successfully manage and coordinate multiple task demands (Bopp \& Verhaeghen, 2007; Craik, 1977; Craik \& Byrd, 1982; Kliegl, Mayr, \& Oberauer, 2000; Kramer et al., 1999; Kray \& Lindenberger, 2000; Verhaeghen et al., 1997) above and beyond any general decline in processing speed or capacity (Cerella, 1985; Salthouse, 1996; Verhaeghen, Steitz, Sliwinski, \& Cerella, 2003). In line with this assumption, older adults can seemingly efficiently deploy their cognitive resources to perform task switches, as illustrated by the lack of age-related differences in local task-switching costs (i.e., a difference between switch and non-switch trials within a mixed block), but they are impaired when maintaining and coordinating multiple task sets (Verhaeghen, 2013; Verhaeghen, Cerella, Bopp, \& Basak, 2005). More broadly, age-related deficits in attentional-executive working memory control have been posited as a mechanism to explain age-related declines in a wide array of tasks assessing higher-level cognition, either as a direct cause (Hasher \& Zacks, 1988; Mayr \& Kliegl, 1993) or as a link between a general decrease in executive resources and higher-order cognitive abilities (Dobbs \& Rule, 1989; Morris, Craik, \& Gick, 1990; Salthouse, 1996).

The conclusion that a main source of age-related working memory storage impairment is a difficulty in effectively managing multiple task sets has been challenged by a series of studies reporting that, under certain conditions, older adults can coordinate simultaneous storage and processing demands just as well as their younger counterparts. Many investigations have resulted in little to no age-related processing costs to memory (e.g., M. Anderson, Bucks, Bayliss, \& Della Sala, 2011; A. D. Baddeley, Baddeley, Bucks, \& Wilcock, 2001; De 
Ribaupierre \& Ludwig, 2003; Gick et al., 1988; Logie et al., 2004). For example, in contrast to Bopp and Verhaeghen (2005), in a meta-analysis of studies from their lab using simple and complex span tasks, Jenkins, Myerson, Hale, and Fry (1999) found no evidence that age effects on memory performance were larger for tasks in which memoranda are mixed with processing episodes, relative to storage only paradigms (see also Hale et al., 2011; Jenkins, Myerson, Joerding, \& Hale, 2000; Rose, Myerson, Sommers, \& Hale, 2009). Notwithstanding differences in inclusion criteria, the findings from Jenkins, Myerson, Hale, and Fry (1999) seem hard to reconcile with the view that age-related depletion of executive resources impairs the coordination of storage with ongoing processing. In the sections that follow, we highlight methodological discrepancies between studies that preclude an unambiguous interpretation of such findings.

\section{Possible Moderators of Processing Costs to Memory Performance}

Titration of Task Difficulty. One key characteristic of studies that have not found significant age differences in the effects of processing on storage is in the use of titration of task demands. Somberg and Salthouse (1982) pointed out that the interpretation of age differences under conditions of divided attention (i.e., dual task) is complicated when there are age differences under full attention (i.e., single task). Larger age differences under dual task relative to single need not imply that older adults have a disproportionate difficulty in coordinating the competing task demands (see Loftus, 1978; Salthouse, 2000). One way around this, they argue, is to adjust the level of demand of the individual tasks prior to their combination. Indeed, several studies have adjusted the demand of storage (e.g., digit span) and processing (e.g., visuospatial tracking) tasks and found no significant difference in the extent of concurrence costs between younger and older participants when these tasks are performed simultaneously (e.g., M. Anderson et al., 2011; A. D. Baddeley et al., 1986; Logie et al., 2004; Logie, Della Sala, MacPherson, \& Cooper, 2007; MacPherson, Della Sala, \& Logie, 2004; MacPherson, Della Sala, Logie, \& Wilcock, 2007).

While studies adopting titration have tended to find no differential age effect on storage+processing performance, there have been contrary reports in the literature (e.g., Bier et al., 2017; Rhodes et al., 2019). Further, many of the studies failing to find an age by task interaction have also had very small sample sizes ( $<10$ per group: A. D. Baddeley et al., 2001, 1986; Logie et al., 2004). Thus, rather than an effect of titration, it may be the case that lack of power is the primary contributor to these differential findings. With meta-analysis we are ideally placed to evaluate this; by synthesizing the results of a range of studies that have used titration of task demand, and comparing them to those that have not, we are able to conduct a far more powerful test of the role of titration than any isolated study in the literature.

The issue of comparing storage+processing costs between younger and older adults when they differ in single task performance has received some scrutiny in the broader dual task literature in the meta-analysis conducted by Riby et al. (2004). Unexpectedly, controlling for baseline differences in performance between younger and older adults appeared not to have an effect on the size of the age-related deficit. Upon closer inspection, however, only four studies included used actual titration procedures to adjust task difficulty to the ability of each participant prior to assessment of dual task performance. The other studies attempted to control for baseline differences statistically by using proportional change scores. 
There is, at present, no consensus as to the most suitable metric for measuring and analyzing dual task performance. Depending on their application, absolute and proportional dual task costs vary in their relative conservativeness and, to our knowledge, there is no clear reason to favor one over the other for working memory paradigms (for discussion, see, Guttentag, 1989). Rather, adjusting single task difficulty to try and eliminate differences between groups makes this choice irrelevant and allows researchers to compare groups with a common baseline (cf. Salthouse, Rogan, \& Prill, 1984; Somberg \& Salthouse, 1982). As such, this approach has become popular in the literature on working memory (M. Anderson et al., 2011; A. D. Baddeley et al., 1986; Logie et al., 2004, 2007; MacPherson et al., 2004, 2007) and we assess the role of titrating task demand (particularly that of the storage task) on effect sizes.

Domain of Storage and Processing Tasks. It is well established that the extent to which processing tasks disrupt storage is driven by the kind of operations required and the type of stimuli used for both tasks. The retention of verbal material is disrupted to a larger degree by a processing task requiring verbal operations (e.g., naming) than when the processing task requires visuospatial operations (e.g., pointing). Similarly, memory for visual information has been found to be disrupted more by visual relative to verbal processing (e.g., Bayliss, Jarrold, Gunn, \& Baddeley, 2003; Cocchini, Logie, Della Sala, MacPherson, \& Baddeley, 2002; Farmer, Berman, \& Fletcher, 1986; Hale \& Myerson, 1996; Logie, Zucco, \& Baddeley, 1990; Meiser \& Klauer, 1999; Myerson, Hale, Rhee, \& Jenkins, 1999; Shah \& Miyake, 1996; Thalmann \& Oberauer, 2017), although visual information has also been found to be more generally susceptible to interpolated processing tasks (e.g., C. C. Morey \& Bieler, 2013; C. C. Morey, Morey, Reijden, \& Holweg, 2013).

Task domain is also an important determinant of age-related differences in performance on working memory tasks. In general, age effects in the verbal domain tend to be relatively small compared to those in the visuospatial domain (e.g. Jenkins et al., 1999; Johnson, Logie, \& Brockmole, 2010). However, it is not clear that age differences in storage+processing performance are exacerbated when the two tasks overlap in domain. For example, in their second experiment, Jenkins et al. (2000) combined verbal or spatial span tasks with either verbal or spatial processing tasks. They observed domain-specific interference but found no evidence that this was exacerbated in older adults, suggesting that domain overlap may not affect older adults' ability to simultaneously store and process. Nevertheless, we use the current meta-analytic data sets to gain another vantage point on this issue.

In addition to assessing the domain tapped by the storage and processing tasks, we looked at the role of the input and output modalities of the two tasks and whether they overlapped. We were particularly interested in input modality due to the possibility of interference between the to-be-remembered material and the processing material. For example, when verbal memoranda are presented visually there appears to be interference from a visual concurrent task suggesting the reliance on visual codes (Logie, Della Sala, Wynn, \& Baddeley, 2000; Logie, Saito, Morita, Varma, \& Norris, 2016). Given the proposed age-related susceptibility to interference (e.g., Hasher \& Zacks, 1988), we assessed input and output modality as potential moderators. Note that Verhaeghen et al. (2003) also looked at overlap in input modality in their meta-analysis of the broader dual tasking and aging literature. In this case overlap in input modality was found to reduce age-related slowing under dual task conditions but increase age differences in accuracy. 
The Nature of the Processing Task. So far we have used the term "processing" in a general sense to refer to some other activity performed while retaining a memory load. However, there are a wide range of processing tasks used in the literature that differ in the demands they place on the participant. These different demands may influence the extent to which older adults can simultaneously store and process information. For example, many of the studies that report little or no age differences in storage+processing performance use motor tasks, such as tracking a moving object (A. D. Baddeley et al., 1986; Logie et al., 2004) or ticking off boxes joined in a particular sequence (A. D. Baddeley et al., 2001; De Ribaupierre \& Ludwig, 2003). More cognitively demanding concurrent tasks, on the other hand, may increase age differences in storage performance (e.g., Salthouse, 1990). Consequently, we coded processing tasks by whether they were primarily sensorimotor in nature (e.g., tracking, manual box-crossing, articulatory suppression) or whether they imposed a cognitive load (e.g., mental arithmetic, sentence verification, mental rotation). There were also several studies in which the secondary task required participants to retain another memory load, providing a third category.

As mentioned above, many of the studies that have found no age-related increase in storage+processing dual task costs have also titrated the level of demand prior to combining tasks. However, in a recent experiment, we titrated both a serial order letter recall task and a task involving the verification of single digit sums and found that the dual task cost for the serial recall task increased substantially with age (Rhodes et al., 2019). This is at odds with the other studies that have found no such cost under titration. We noted that a key aspect of our paradigm was the imposition of a response deadline (i.e., participants had to respond to each processing item within a given time period or their response would be marked incorrect). This contrasts with many other experiments in which no response

deadline is imposed. Interestingly, there have been some reports of age-related slowing on titrated secondary tasks alongside small or no age differences in storage performance (Bier et al., 2017; Logie et al., 2007). We speculated that processing tasks without a strict response deadline allow older adults to strategically sacrifice speed of processing in favor of performing maintenance activities on the memory load. Thus, in the present meta-analysis we categorized processing tasks as those that do and do not impose a deadline on responding.

\section{The Current Meta-Analysis}

When used judiciously, meta-analysis is a powerful statistical technique. Here, it enables us to improve the power of small or inconclusive studies and to identify sources of diversity across various types of paradigms. A potential drawback of the meta-analytic approach is that averaging across group means forces us to skim over a lot of methodological details. To quote Verhaeghen et al. (2005), we are considering "the forest, rather than the trees" (p. 173). Since studies posing the exact or similar questions that are included in a meta-analysis can be expected to vary in a number of ways, methodological nuances tend to get lost as a result of data averaging. The distinct advantage here is that any effect robust enough to emerge in a meta-analysis is likely to be genuine and credible. In order to minimize the effects of the inherent bias toward averaging across group means, we applied strict study selection criteria and compared only paradigms in which at least one of the concurrent tasks involved short-term memory storage. This is a marked departure from previous meta-analyses of dual tasking and aging conducted by Riby et al. (2004) and 
Verhaeghen et al. (2003) which were concerned with dual tasking more broadly and included any combination of two concurrent activities.

We focused on situations where a storage task is combined with some form of ongoing processing and chose to omit studies comparing different levels of memory updating (e.g., 1-back versus > 1-back tasks: Verhaeghen \& Basak, 2005; Verhaeghen \& Hoyer, 2007) or updating one versus more than one stream of information (e.g., Göthe, Oberauer, \& Kliegl, 2007). While such updating tasks almost certainly involve processes similar to those required to manage the ongoing retention of information in the face of distraction, they also differ in a number of ways (e.g., the "target" of memory storage changes throughout the course of a trial) that may introduce more heterogeneity into the observed age differences. Furthermore, Bopp and Verhaeghen (2018) have recently reported a meta-analysis focusing specifically on n-back paradigms. They reported a marked increase in age differences in accuracy when $\mathrm{n}>$ 1 , an effect they attribute to an age deficit in maintaining or retrieving items from outside the focus of attention.

To thoroughly assess whether the literature requires that we assume a specific agerelated deficit in working memory storage during concurrent processing, we searched for any study in which performance of younger and older adults was compared, and in which memory performance with no secondary task and memory performance with some processing task was assessed. For reasons outlined in detail above, we sought to explore possible moderators responsible for the inconsistency in the magnitude of the age effects reported in the literature. To this end, we assessed: 1) the impact of equating (i.e., titrating) single task performance across age groups before concurrent tasks are combined, 2) whether the stimulus material used in the tasks is verbal or nonverbal in nature (and whether there is an overlap between domains of storage and processing components), 3) the processing requirements of the secondary task, 4) whether the input/output modality for the storage task matches the input/output modality for the processing task, and 5) whether the processing task imposes a response deadline. To preview our results, the analyses of titration and task domain point towards an influence of these factors on age differences in storage+processing performance, whereas there is no clear evidence of moderation by the other factors. Therefore, the results for titration and domain are presented in the main manuscript and detailed results for the remaining moderators are reported in the supplement.

As discussed above, it is well known in the cognitive aging literature that an age-by-task interaction does not necessarily imply that the age effect is disproportionate (e.g., Salthouse, 2000; Verhaeghen, 2013). What appears as a specific deficit may often be explained by age-related change in a single mechanism (see Dunn \& Kirsner, 1988; Loftus, 1978). One way of addressing this is the Brinley plot (Brinley, 1965) which presents the performance of older adults as a function of the performance of younger adults for each observation in the meta-analysis (for examples, see, Cerella, 1985, 1990; Cerella, Poon, \& Williams, 1980; Myerson \& Hale, 1993; Sliwinski \& Hall, 1998; Verhaeghen et al., 2003). In analyzing the Brinley plot we attempt to identify whether a single function can relate younger and older adults' performance or whether separate functions are needed for different tasks. In the present situation, separate functions for single (storage only) and dual (storage+processing) tasks might suggest that older adults' ability to retain information over brief intervals is disproportionately impaired by a concurrent task. This method is closely related to state-trace analysis (Bamber, 1979; Prince, Brown, \& Heathcote, 2012), which has also 
been applied in meta-analyses of the aging literature (e.g., Mayr, Kliegl, \& Krampe, 1996; Verhaeghen et al., 2003), in which performance on one task is plotted as a function of performance on another task and the analysis attempts to identify separate functions for different age groups. We use both techniques in the present meta-analysis in an attempt to reveal the dimensions in the data (see Verhaeghen, 2013), which in turn helps us to address the question of whether older adults specifically struggle to retain information in working memory when undertaking a concurrent processing task.

\section{Sample of Studies}

A search was carried out using the Web of Science, PsycINFO, Ovid MEDLINE, and Embase bibliographic databases. Additionally, we used the data from selected published studies included in the meta-analysis by Riby et al. (2004) and Verhaeghen et al. (2003). We supplemented these searches with articles identified from reference sections and suggestions from colleagues in the area of working memory and cognitive aging.

The search was conducted in April and May 2017 by querying a conjunction of two sets of search terms, one targeting age differences (age, ageing/aging, young/younger, old/older) and another to detect papers using dual task methods (dual task, dual tasking, concurrent task, concurrent activity, storage and processing, complex span). The search strings were adjusted for each database depending on the size of the corpus, functional differences of Boolean operators, and advance search functions. Only studies reported in English were included. There were no searching restrictions on publication date or status. The literature search was updated in November 2018 by searching PsycINFO database.

Study selection was conducted in two stages: an initial screening of titles and abstracts to identify potentially relevant papers followed by screening of the full papers identified as possibly relevant in the initial screening against the inclusion criteria. Parallel independent assessments were conducted by AJ and SR to minimize the risk of errors. Disagreements were resolved through discussion. Inclusion criteria were as follows: 1) the study contained experiments in which a comparison was made between healthy younger adults (with a mean age of 30 years or younger) and older healthy adults (with a mean age of 60 years and older); 2) the study compared latencies, accuracy, or both for a storage task under dual task conditions with the corresponding measure of single task performance, and 3) at least one of the concurrent tasks involved short-term memory storage. See Figure 1 for a flowchart of the screening process.

We do not claim to have found each and every published instance of an aging study using a short-term storage task with and without a processing load using these search methods. Many reports focusing on other elements of cognition, but including short-term storage measures, likely eluded our search. Likewise, papers focusing on memory more generally but measuring working memory specifically might have slipped through. Nonetheless, despite restricting our search to studies that included very specific dual task paradigms combining storage and processing of information, our search yielded more publications (45) than previous attempts by Riby et al. (2004) and Verhaeghen et al. (2003) (34 and 31, respectively).

When a study was relevant for our meta-analysis but necessary data were not reported, or reported only in a figure, we contacted authors via email to obtain the data. We only emailed authors for articles published after the year 2000. Of the 14 emails sent we received 


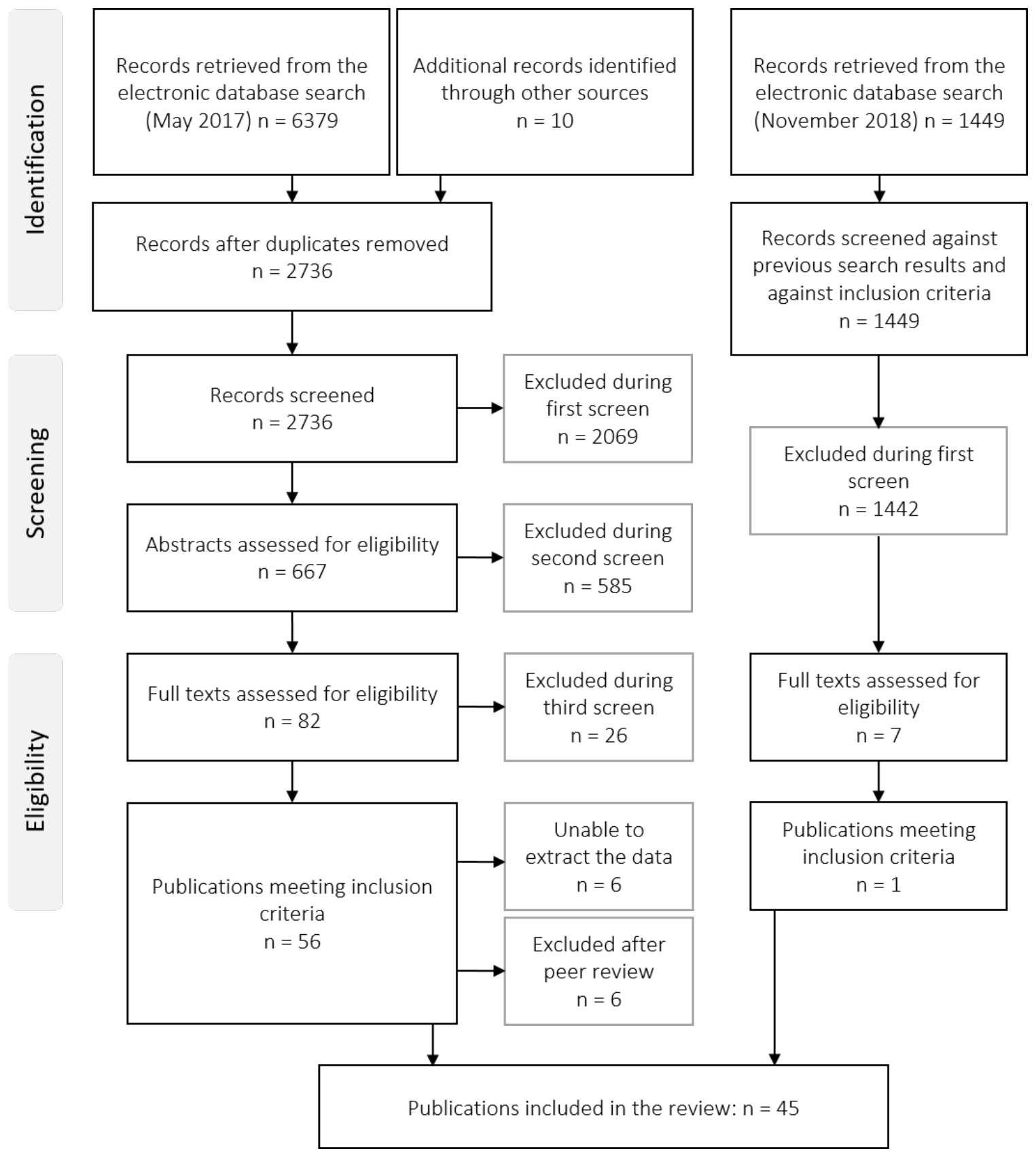

Figure 1. Flowchart of the screening process. 
data from 4 groups. In addition we received data for several experiments from our colleague, Robert Logie. ${ }^{1}$ When the relevant data were presented only graphically, and could not be obtained directly from the authors, they were extracted using WebPlot Digitizer Version 3.12 (https://automeris.io/WebPlotDigitizer/). In general, we chose not to collapse across other factors manipulated in the original manuscript, unless the data in the original publication were only reported in that manner. For example, if a single manuscript reported the same storage task varying the number of to-be-remembered items, or the length of a retention interval, we considered each mean reported at each level of those independent variables to be individual data points (clustering of data points was handled by our hierarchical modeling approach, described below).

\section{Data Coding}

We extracted the following study characteristics: list of authors, year of publication, sample size, participants' mean age in each group, average reaction times and accuracy measures (and estimates of variance where available) for the storage task in single and dual task conditions. We also summarized what each storage and processing task involved (see Table 1) and coded whether the researchers obtained a measure of each individual's ability to perform the single tasks (i.e., storage or processing, or both) in isolation and then used this to titrate the level of difficulty. Based on the nature of the stimulus material each task was dichotomously coded as verbal when including words, digits, or letters as stimuli, or as nonverbal when including other kinds of stimuli (such as pictures, non-linguistic sounds, or shapes). Processing tasks were additionally categorized as either cognitive (e.g., arithmetic), sensorimotor (e.g., tracking a moving target), or tasks requiring some other form of storage. Finally, we coded whether the input/output modality for the storage task matched the input/output modality for the processing task.

\section{Accuracy and Reaction Time Data Sets}

Table 1 presents a listing of all publications included in the analyses. The accuracy data set includes 43 references contributing 135 dual task observations and 96 unique single task observations. Three additional observations were excluded as they had ceiling level performance in one or both conditions (Vaportzis, Georgiou-Karistianis, \& Stout, 2013; Voelcker-Rehage \& Alberts, 2007; Voelcker-Rehage, Stronge, \& Alberts, 2006). Reaction times were extracted from 8 publications, yielding 18 dual task observations and 16 unique single task observations. Overall, variance estimates (standard deviations or errors) were not reported for 22 and 12 observations for accuracy and latency measures, respectively. To estimate variance for these studies we calculated the typical ratio of SD to the mean for the studies that did report SD or SE (SE was converted into SD via the sample size). This ratio was calculated separately for younger and older groups, and for single and dual task conditions. We then approximated SD, for studies not reporting this, by multiplying mean accuracy by the ratio. While this is clearly a simplification, analyses with the restricted set of studies that did report estimates of variance led to the same conclusions.

\footnotetext{
${ }^{1}$ We would also like to thank Mihalis Doumas, Paul Verhaeghen, Katherine Gamble, and Bianca Bier for providing data from their experiments.
} 
Although we report both data sets here, our focus is on findings stemming from the analyses of accuracy, as the interest in these studies is typically in the amount of information available at test, rather than the speed with which it is accessed. Therefore, accuracy is a more meaningful, and more widely used, outcome in the studies that we look at (see Table 1). For this reason, the results concerning reaction time data should be considered secondary. Further, as described below, our assessment of reaction time is limited by the small number of studies in this literature reporting latency data.

Table 1

Sample of studies. Additional information (e.g., sample size, mean group age, average accuracy, input/output modality, task domain, task type) can be found at https://osf.io/bp359/. Note: $A R=$ included in accuracy and RT analyses, $R=$ inluded only in $R T$ analysis

\begin{tabular}{|c|c|c|c|}
\hline Reference & Storage Tasks & Processing Tasks & Titration \\
\hline Anderson et al. (2011) Exp 1 & Digit recall & Visual discrimination & Yes \\
\hline $\begin{array}{l}\text { Babcock and Salthouse (1990) Exp } \\
2 \text { and } 3\end{array}$ & Digit recall & Arithmetic & Yes \\
\hline Baddeley et al. (2001) Exp 3 & Digit recall & Manual box-crossing & Yes \\
\hline Baddeley et al. (1986) & Digit recall & Visuospatial tracking & Yes \\
\hline Baron and Mattila $(1989)^{\mathrm{R}}$ & Auditory or visual recognition & Auditory or visual recognition & No \\
\hline Bier et al. (2017) Exp 1 and 2 & Digit recall & Visuospatial tracking & Yes \\
\hline Caljouw et al. (2016) & Visuospatial memory task & Sequence learning & Relative \\
\hline Clapp and Gazzaley $(2012)^{\mathrm{AR}}$ & Delayed recognition task & Visual categorization & No \\
\hline Clapp et al. $(2011)^{\mathrm{AR}}$ & Delayed recognition task & Visual categorization & No \\
\hline de Ribaupierre and Ludwig (2003) & $\begin{array}{l}\text { Digit recall, visuospatial recall, } \\
\text { word recall }\end{array}$ & $\begin{array}{l}\text { Manual box-crossing, word recall, } \\
\text { visuospatial recall, sentence verifi- } \\
\text { cation }\end{array}$ & Adaptive \\
\hline Della Sala et al. (2010) & Digit recall & Visuospatial tracking & Yes \\
\hline Dumas and Hartman (2008) Exp 1 & Delayed matching-to-sample & Letter comparison task & Yes \\
\hline Foley et al. (2015) & Digit recall & Visuospatial tracking & Yes \\
\hline Gamble et al. (2014) & Probed recognition & Target detection & Relative \\
\hline Gick et al. (1988) & Word recall & Sentence verification & No \\
\hline $\begin{array}{l}\text { Holtzer et al. (2004) Exp } 1 \text { and } \\
2^{\text {AR }}\end{array}$ & $\begin{array}{l}\text { Delayed recognition task, digit re- } \\
\text { call }\end{array}$ & $\begin{array}{l}\text { Delayed recognition task, digit re- } \\
\text { call }\end{array}$ & No \\
\hline Holtzer et al. (2005) & Delayed recognition task & Digit recall & No \\
\hline Kempe et al. $(2015)^{\mathrm{AR}}$ & Word recall & Ordered word recall & No \\
\hline $\mathrm{Li}(1999) \operatorname{Exp} 1$ and 2 & Word recall, digit recall & Arithmetic verification & No \\
\hline Logie et al. (2004) Exp 2 and 3 & Digit recall & Visuospatial tracking & Yes \\
\hline Logie et al. (2007) Exp 1 & Digit recall & Simple RT task & Yes \\
\hline Logie et al. (2007) Exp 2 & Digit recall & Choice RT task & Yes \\
\hline MacPherson et al. (2004) & Digit recall & Visuospatial tracking & Yes \\
\hline MacPherson et al. (2007) & Digit recall & $\begin{array}{l}\text { Visuospatial tracking, visuospatial } \\
\text { pattern recall, articulatory suppres- } \\
\text { sion }\end{array}$ & Yes \\
\hline McCabe and Hartman (2003) & Word recall & $\begin{array}{l}\text { Lexical decisions, sentence reading, } \\
\text { word reading }\end{array}$ & No \\
\hline Morris et al. (1990) Exp 1 and 2 & Word recall & Sentence verification & No \\
\hline $\begin{array}{l}\text { Peterson and Naveh-Benjamin } \\
\text { (2016) Exp } 1\end{array}$ & $\begin{array}{l}\text { Colour recognition, shape recogni- } \\
\text { tion, binding recognition }\end{array}$ & Articulatory suppression & No \\
\hline $\begin{array}{l}\text { Peterson and Naveh-Benjamin } \\
\text { (2016) Exp } 2\end{array}$ & $\begin{array}{l}\text { Item recognition, location recogni- } \\
\text { tion, binding recognition }\end{array}$ & $\begin{array}{l}\text { Articulatory suppression, back- } \\
\text { ward counting }\end{array}$ & No \\
\hline $\begin{array}{l}\text { Peterson and Naveh-Benjamin } \\
\text { (2016) Exp } 3\end{array}$ & $\begin{array}{l}\text { Item recognition, location recogni- } \\
\text { tion, binding recognition }\end{array}$ & Articulatory suppression & No \\
\hline Rekkas (2006) & Letter recall & $\begin{array}{l}\text { Articulatory suppression, digit re- } \\
\text { versal }\end{array}$ & Yes \\
\hline Rhodes et al. (in press) & Letter recall & Arithmetic verification & Yes \\
\hline Robertson et al. (2006) & Letter and number forward recall & $\begin{array}{l}\text { Letter and number sequenced re- } \\
\text { call, colour naming }\end{array}$ & No \\
\hline Rogers et al. $(1994)^{\mathrm{R}}$ & ognition & Visual target detection & No \\
\hline Rose et al. (2009) & $\begin{array}{l}\text { Letter and number forward recall, } \\
\text { spatial recall, letter and number } \\
\text { forward recall and tapping, spatial }\end{array}$ & $\begin{array}{l}\text { Letter and number sequenced re- } \\
\text { call, updating, letter and number } \\
\text { sequenced recall and tapping }\end{array}$ & No \\
\hline
\end{tabular}




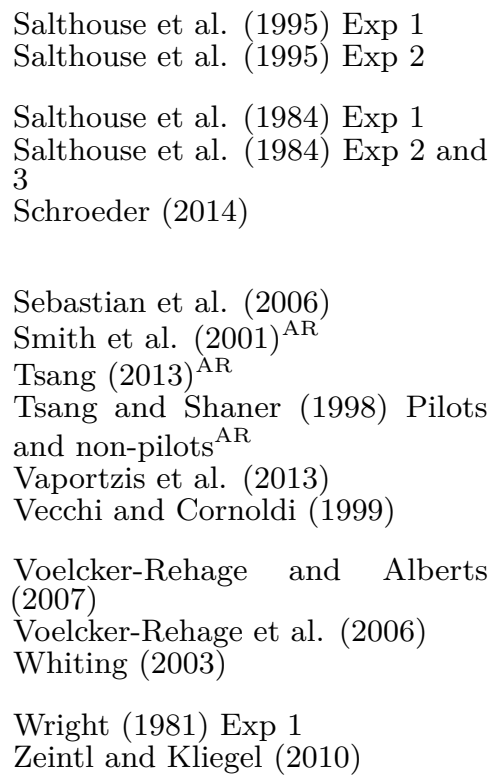

\author{
Letter recall \\ Letter recall \\ Digit or letter recall \\ Cued digit or letter recall \\ Self-paced word recall, timed word \\ recall \\ Digit recall \\ Word list recognition \\ Visual recognition \\ Letter recognition \\ Digit recall, backward digit recall \\ Visual pattern recall, word recall \\ Letter 1-back \\ Letter 1-back \\ Word recall \\ Digit recall \\ Word recognition (in operation \\ span task)
}

$\begin{array}{ll}\begin{array}{l}\text { Symbol verification } \\ \text { Symbol verification, identity verifi- } \\ \text { cation, arithmetic verification } \\ \text { Letter recall }\end{array} & \text { No } \\ \text { Cued letter recall } & \text { Yes } \\ \begin{array}{l}\text { Self-paced reading span, self-paced } \\ \text { sentence span, timed reading span, }\end{array} & \text { No } \\ \text { timed sentence span } & \\ \begin{array}{l}\text { Manual box-crossing } \\ \text { Arithmetic verification }\end{array} & \text { Yes } \\ \begin{array}{l}\text { Mental rotation } \\ \text { Visuospatial tracking }\end{array} & \text { Relative } \\ & \text { No } \\ \begin{array}{l}\text { Simple RT task, complex RT task } \\ \text { Mental rotation, sentence verifica- }\end{array} & \text { No } \\ \text { tion } & \text { No } \\ \text { Grip force task } & \text { No } \\ \begin{array}{l}\text { Grip force task } \\ \text { Letter recall at encoding, letter re- } \\ \text { call at retrieval }\end{array} & \text { No } \\ \begin{array}{l}\text { Verbal reasoning } \\ \text { Word reading }\end{array} & \text { No } \\ & \text { No }\end{array}$

Symbol verification

Letter recall

Self-paced reading span, self-paced sentence span, timed reading span, Manual box-crossin

Arithmetic verification

Mental rotation

Simple RT task, complex RT task Mental rotation, sentence verification

Grip force task

Verbal reasoning

No

\section{Statistical Analyses}

For statistical analyses, we used the metafor package (Viechtbauer, 2010) in $R$ ( $R$ Core Team, 2018). ${ }^{2}$ The data and $\mathrm{R}$ scripts for the reported analyses are available at https://osf.io/bp359/.

Age differences in single (storage only) and dual (storage+processing) performance were expressed as standardized mean differences (Hedges' $g$; Hedges, 1981) using the means and SDs reported for each study (see below for treatment of missing SDs). These effect sizes were synthesized using a random effects meta-analysis to model the likely heterogeneity in "true" effect sizes owing to variations in methodology. To model this heterogeneity we included a random effect of Study to acknowledge this clustering. We assumed that the $i$ th effect size $(g)$ from the $j$ th study is drawn from a normal distribution:

$$
g_{i j} \sim \operatorname{Normal}\left(\mu_{i j}, v_{i j}\right)
$$

where $v_{i j}$ is the sampling variance associated with the observation. In the base model the "true" effect size was modeled as follows:

$$
\mu_{i j}=\beta_{0}+b_{j}
$$

where $\beta_{0}$ is the average "true" effect and $b_{j}$ is the random deviation around this average associated with study $j$. These deviations are assumed to be normally distributed: $b_{j} \sim \operatorname{Normal}\left(0, \tau^{2}\right)$, with $\tau$ capturing the heterogeneity in effect sizes between studies.

\footnotetext{
${ }^{2}$ This paper was written in markdown in $\mathrm{R}$ using the papaja package (Aust \& Barth, 2018). We also made use of the tidyr and xtable packages (Dahl, 2016; Wickham \& Henry, 2018).
} 
These base meta-analytic models were expanded into meta-regressions to address potential moderators of the size of age differences. For example, to include a binary moderator (e.g., titrated vs not titrated) we would expand the equation above to add an additional parameter, such that $\mu_{i j}=\beta_{0}+x_{i j} \alpha+b_{j}$. Here $x_{i j}$ is an indicator set to zero or one depending on the value of the binary moderator for observation $i$ of study $j$ and $\alpha$ provides an estimate of the influence of the moderator on effect sizes (see Viechtbauer, 2010 for more detail).

Note that the above analyses do not specifically address the question of how the magnitude of age-related differences varies between storage and storage+processing tasks. For that we would need to know the size of the difference between storage and storage+processing performance for each group and its associated error. This second aspect, the error, presents a problem when the correlation between storage and storage+processing for each age group in each study is not known. As this information is typically not reported, we necessarily had to assume correlations to analyse the disparities between age groups in the difference between storage and storage+processing performance (i.e., the paired standardized mean difference). In our analyses we assumed a range of positive correlations of different magnitudes to calculate the SD of the storage vs storage+processing task difference for each age group $(0.3,0.5,0.7,0.9)$. The magnitude of the assumed correlation clearly affects the size of the standardized difference, but the general conclusions of our analyses were unchanged by this choice. To justify reporting a particular assumed correlation we consulted our own data set (Rhodes et al. (2019); $\mathrm{N}=164$ ) of participants' performance on a serial recall task alone and with a concurrent arithmetic verification task. Averaging across dual task conditions, we find a correlation between storage only and storage+processing performance of 0.421 (95\% confidence interval $[0.286, .539]$ ), which is similar to the partial correlation controlling for age $0.455[.320, .570]$. Thus, greater weight should be placed on the analyses assuming between task correlations of 0.3 or 0.5 . We assume $r=0.5$ in the manuscript and report the remaining results in the supplement.

To assess the dimensions in the data we also analyzed the Brinley and state-trace plots of the meta-analysis data set. As Sliwinski and Hall (1998) pointed out, when evaluating Brinley functions it is important to account for potential clustering among observations within studies; therefore, we used a hierarchical model with study level effects and slopes for the effect of task. We also adapted the model to make better use of the available information. Specifically, in Brinley analyses researchers typically perform a weighted regression predicting older performance by younger performance with the weights determined by sample size (see, e.g., Verhaeghen et al., 2003). However, this standard regression model, or its hierarchical variant, imposes the assumption that younger adult performance (used as the predictor) is measured without error, which clearly is not the case (for this point see also, Ratcliff, Spieler, \& Mckoon, 2000, 2004). Further the error associated with the older adult performance (used as the outcome) is assumed unknown and is estimated. Typically, the variance of younger and older group performance is reported in the original studies; thus, previous assessments of Brinley functions in meta-analyses of the cognitive aging literature have not incorporated all of the available information. We apply a model that incorporates estimates of variability and models the fact that both groups' performance is measured with error. This model is also applied in the analysis of the state-trace plot, where storage and storage+processing task data are used as predictor and outcome variables. 
In this model the variables that form the $x$ and $y$ axes of the plot are both assumed to be normally distributed with known error:

$$
\begin{aligned}
& y_{i j} \sim \operatorname{Normal}\left(\eta_{i j}, s_{y i j}^{2}\right) \\
& x_{i j} \sim \operatorname{Normal}\left(\lambda_{i j}, s_{x i j}^{2}\right)
\end{aligned}
$$

where $s_{y i j}$ and $s_{x i j}$ are the standard errors for the $y$ and $x$ axes, respectively. In this case $\lambda_{i j}$ is the "true" value of the predictor, thereby acknowledging that it is measured with error. In the basic model (Model 1), the following equation is used to determine the value of $\eta$ :

$$
\mathcal{M} 1: \eta_{i j}=\beta_{0}+\beta_{1} \lambda_{i j}+b_{0 j}+b_{1 j}
$$

where $\beta_{0}$ and $\beta_{1}$ are the population level intercept and slope parameters, respectively. The parameters $b_{0 j}$ and $b_{1 j}$ allow for study level differences in intercepts and slopes, respectively. ${ }^{3}$

Model 2 includes separate intercepts - for tasks in the case of Brinley or age groups in the case of state-trace analysis:

$$
\mathcal{M} 2: \eta_{i j}=\beta_{0}+\beta_{1} \lambda_{i j}+\beta_{2} I_{i j}+b_{0 j}+b_{1 j}
$$

where $I_{i j}$ is an indicator that codes for different tasks or groups.

In Model 3, an additional parameter is added to allow for differences in slope based on task or group:

$$
\mathcal{M} 3: \eta_{i j}=\beta_{0}+\beta_{1} \lambda_{i j}+\beta_{2} I_{i j}+\beta_{3} I_{i j} \lambda_{i j}+b_{0 j}+b_{1 j}
$$

These models are estimated using the R package brms (Bürkner, 2017, 2018) which serves as an interface to the Bayesian modeling language Stan (B. Carpenter et al., 2016). More details on the models and the priors used are provided in the supplement.

\section{Results}

\section{Age-Related Differences in Accuracy}

The meta-analysis of the available storage task data, unsurprisingly, revealed an age effect on accuracy. The weighted standardized mean difference (and 95\% confidence interval) is $0.604[0.382,0.825](z=5.343, p<0.01)$ (test for heterogeneity: $Q(95)=453.624, p<$ 0.01). For storage+processing task data the mean difference is approximately the same size at $0.638[0.419,0.858](z=5.7, p<0.01)(Q(134)=627.993, p<0.01)$. While this might

\footnotetext{
${ }^{3}$ As is typical in hierarchical modeling, these study level parameters are assumed to be drawn from a zero centered multivariate normal distribution.
} 
suggest that age effects in storage and storage+processing task performance are comparable, note that full evaluation of this question requires us to assess age-related differences in task differences.

In an attempt to analyse the age-related difference in the dual task cost (i.e., the difference between storage and storage+processing) we calculated paired mean differences and their standard deviations assuming a correlation of 0.5 for both age groups (similar results with $0.3,0.5,0.7$, and 0.9 correlations are presented in the supplementary materials). Storage+processing task performance was subtracted from storage task performance, consequently larger positive scores reflect a larger concurrence cost. The standardized mean difference for this paired measure was estimated as $-0.182[-0.282,-0.082](z=-3.568, p<$ $0.01)(Q(134)=316.417, p<0.01)$. The negative sign of this coefficient suggests that the single - dual task difference is smaller for younger adults relative to older. The size of this effect is small and should be interpreted carefully as it depends on a particular correlation assumption (estimates varied from -0.16 to -0.28 for assumed correlations of 0.3 and 0.9 , respectively. In each case the 95\% CI excluded 0) and, more importantly, that the relation between tasks is the same strength for both groups. Note, the Brinley and state-trace analyses presented below reach a similar conclusion, and do not rely on assumed correlations.

In summary, the meta-analyses of age-related differences reveal considerable discrepancy in performance on storage tasks both in single and dual task conditions $(g \approx .6)$. Assuming various positive correlations between accuracy in these conditions, a meta-analysis of the difference between single and dual performance yields a small age effect ( $g$ between -0.16 and -0.28$)$, consistent with a greater age-related difference in storage performance when concurrent processing is required.

In all of the above meta-analyses Cochran's $Q$ tests revealed larger variability, or heterogeneity, in observed effect sizes than would be expected by sampling variability alone. Including study characteristics in the meta-analysis may account for some of this variability.

Titration. Firstly, motivated by the literature review above, we considered the role of titration of storage demands. For single task age differences, including titration in a meta-regression accounted for significant variability in effect sizes, $Q(1)=7.538, p<0.01$ (test of residual heterogeneity: $Q(89)=373.369, p<0.01$ ). For studies that did not titrate the storage task effect size was $0.776[0.522,1.03]$, whereas for studies that did adjust the difficulty of storage activities this was $0.225[-0.076,0.526]$. Notice that the age-related difference for titrated studies is not significantly different from zero and these two effect sizes differ significantly, $-0.552[-0.945,-0.158](z=-2.745, p<0.01)$. This is expected as storage tasks are titrated before storage+processing tasks are completed (e.g., M. Anderson et al., 2011; Logie et al., 2004).

Including titration in the meta-analysis of storage+processing performance yielded similar results to the storage task analysis. Including titration in a meta-regression accounted for significant variability in effect sizes, $Q(1)=7.985, p<0.01$ (residual heterogeneity: $Q(127)=548.848, p<0.01)$. For studies that did not titrate the dual task effect size was $0.845[0.577,1.113]$, whereas for studies that did this was 0.249 [-0.065, 0.564]. This difference was also, itself, significant, $-0.596[-1.009,-0.182](z=-2.826, p<0.01)$.

Considering age effects in the paired difference between storage and storage+processing task (i.e., concurrence cost), including titration as a moderator did not significantly reduce heterogeneity in effect sizes, $Q(1)=1.583, p=0.208$ (residual heterogeneity: $Q(127)=$ 
307.211, $p<0.01)$. There was a small, significant, age difference in the concurrence cost for studies that did not titrate, $-0.246[-0.38,-0.113]$. The effect size for studies that did titrate was smaller and not significantly different from zero, $-0.111[-0.274,0.053]$. However, these two effect sizes themselves did not differ significantly, $0.135[-0.076,0.346](z=1.258, p=$ $0.208)$.

Of the studies that titrated the demands of the storage task, 19 also titrated the demands of the processing task, whereas 18 did not. Relative to not titrating at all, titrating both tasks $(-0.638[-1.082,-0.195](z=-2.82, p<0.01))$ or the storage task only $(-0.551[-0.997,-0.104](z=-2.414, p<0.05))$ had similar effects on age differences in storage+processing performance. This was also the case for the difference score between storage only and storage+processing (titrate both: $0.114[-0.138,0.366](z=0.885, p=$ $0.376)$; titrate storage only: $0.155[-0.09,0.4](z=1.242, p=0.214))$.

Task Domain. Next we considered the potential for modulation of concurrence costs via interference between the storage and processing tasks. To assess this possibility we examined whether the domain of the two tasks drives the magnitude of the storage+processing costs. We coded the studies as to whether their storage and processing sub-components were verbal or nonverbal in nature (the latter category including pictures, non-linguistic sounds, or shapes) and whether there was any overlap between the two domains. 61 observations did not have domain overlap between tasks, whereas 74 did. Within those that did have domain overlap, 65 of these cases were verbal tasks and 8 were nonverbal. One study had overlap in both domains and was omitted from these analyses.

For single tasks it seems unwarranted to assess domain overlap as there is no processing task to consider. Therefore, we assessed the effect of the domain of the storage task, whether it was verbal or nonverbal. This led to a significant reduction in heterogeneity, $Q(1)=5.198$, $p<0.05$ (residual: $Q(93)=450.191, p<0.01$ ), and showed that age differences were smaller for verbal storage tasks, 0.553 [0.322, 0.783], than nonverbal tasks, 0.859 [0.546, 1.172] (test of difference: $-0.306[-0.569,-0.043](z=-2.28, p<0.05))$.

For the dual task data, domain overlap between the storage and processing tasks had a moderating effect, accounting for some of the variability in effect sizes, $Q(2)=18.014, p<$ 0.01 (residual: $Q(131)=486.981, p<0.01$ ). The estimated effect size for the age difference was smallest when there was no overlap between the two tasks, 0.429 [0.199, 0.659]. For studies with two verbal tasks the effect size was somewhat larger, 0.699 [0.468, 0.93], and the age difference was largest when the overlap was nonverbal, $1.371[0.929,1.813]$.

Finally, we looked at age differences in the dual task cost (i.e., paired difference) which were not significantly moderated by domain, $Q(2)=4.843, p=0.089$ (residual: $Q(131)$ $=305.213, p<0.01)$. Nevertheless, examining the predicted effect sizes revealed that age differences were larger when there was domain overlap between the two tasks (verbal: $-0.271[-0.398,-0.145]$; nonverbal: -0.127 [-0.412, 0.157]) relative to when there was no overlap $(-0.104[-0.231,0.022])$. However, all of these estimated effect sizes have rather broad confidence intervals. To simplify the model we conducted an additional analysis in which we categorized studies by whether they had overlap between the two tasks (irrespective of whether this was verbal or nonverbal) or not. This led to a significant reduction in heterogeneity, $Q(1)=4.075, p<0.05$ (residual: $Q(132)=305.213, p<0.01$ ). This analysis confirmed that effect sizes were larger when there was overlap between the storage and processing task domains, $-0.252[-0.37,-0.134]$, relative to when there was no overlap, -0.099 
$[-0.223,0.026]$ (difference $=-0.153[-0.302,-0.004](z=-2.019, p<0.05))$.

Combining Titration and Task Domain. Given the results presented above, titration and overlap in the domain of the storage and processing tasks are candidates for modulating age differences in dual task performance and, to a lesser extent, age differences in the effects of processing on storage. However, the assessment is complicated by the fact that studies that did not titrate also tended to be those that had overlap between the domains of the storage and processing tasks. Of the 128 observations that could be clearly categorized: 13 both titrated and had domain overlap, 34 had neither, 57 did not titrate and had domain overlap, and the remaining 24 titrated and had no domain overlap. Since titration and domain overlap were found to moderate effect sizes, we may ask which is the more important factor?

To address this question we entered both effects and their interaction into a metaregression (see Table 2). The intercept reflects studies without titration or overlap, which exhibit a substantial age difference. Domain overlap did not have a clear effect on effect sizes, whereas titration reduced the age difference in storage+processing task performance. Finally, there was no clear evidence of interaction between the two factors.

Table 2

Results of meta-regression of age differences in dual task performance including domain overlap and titration, and their interaction, as moderators.

\begin{tabular}{lllccll}
\hline & Estimate & Std. Error & $\mathrm{z}$ & $\mathrm{p}$ & $\mathrm{CI}$ lower & $\mathrm{CI}$ upper \\
\hline Intercept & 0.72 & 0.16 & 4.47 & $<0.01$ & 0.40 & 1.04 \\
Overlap & 0.19 & 0.14 & 1.36 & 0.173 & -0.08 & 0.46 \\
Titrated & -0.49 & 0.24 & -2.07 & 0.039 & -0.95 & -0.02 \\
Interaction & -0.14 & 0.30 & -0.45 & 0.651 & -0.72 & 0.45 \\
\hline
\end{tabular}

Note. Domain overlap and titration were dummy coded such that the intercept represents studies that had neither domain overlap nor titration.

Table 3 presents the results for the analysis of dual task costs. In this case the intercept (i.e., studies with neither overlap nor titration) showed a slight (but non-significant) age difference. Domain overlap revealed a tendency to make the age-related difference larger, and titration a tendency to make the age-related difference smaller; but in both cases these were not significant moderators. There was no interaction between the two factors.

To summarize, of the moderators we considered, titration appears to play a role. It clearly reduces age differences in both storage only and storage+processing performance. Considering age-related differences in the dual task cost, titration does appear to reduce the small age difference to one that is no longer distinguishable from zero. However, we note that the overall effect of titration on the dual task cost is not itself significant, therefore, some restraint is required in interpreting this result.

Next we turn to Brinley and state-trace analyses to further probe the differential age effect on tasks requiring storage and processing. These address the, possibly more theoretically interesting, question of whether the age effect is disproportionate. 
Table 3

Results of meta-regression of age differences in the dual task cost including both domain overlap and titration, and their interaction, as moderators.

\begin{tabular}{lllcccl}
\hline & Estimate & Std. Error & $\mathrm{z}$ & $\mathrm{p}$ & CI lower & CI upper \\
\hline Intercept & -0.18 & 0.10 & -1.83 & 0.07 & -0.37 & 0.01 \\
Overlap & -0.09 & 0.11 & -0.88 & 0.38 & -0.30 & 0.12 \\
Titrated & 0.13 & 0.14 & 0.98 & 0.32 & -0.13 & 0.40 \\
Interaction & -0.13 & 0.20 & -0.65 & 0.52 & -0.52 & 0.26 \\
\hline
\end{tabular}

Note. Domain overlap and titration were dummy coded such that the intercept represents studies that had neither domain overlap nor titration.

\section{Brinley and State-Trace Plots of Accuracy}

Figure 2 panel A presents the Brinley plot and panel B presents the state-trace plot of accuracy for the 34 references that reported an accuracy measure. In line with previous meta-analyses (e.g., Verhaeghen et al., 2003), we performed a logit transform of accuracy to try and ensure linearity (where $\operatorname{logit}(p)=\ln [p /(1-p)]$ ). Also in line with the approach of Verhaeghen et al. (2003), we performed an ordinary least squares regression to identify outliers or influential cases, of which there were none.

Brinley. To start we considered three models for the Brinley plot: Model 1 predicts performance of older adults from performance of their younger counterparts and fits a

\section{Logit transformed accuracy}
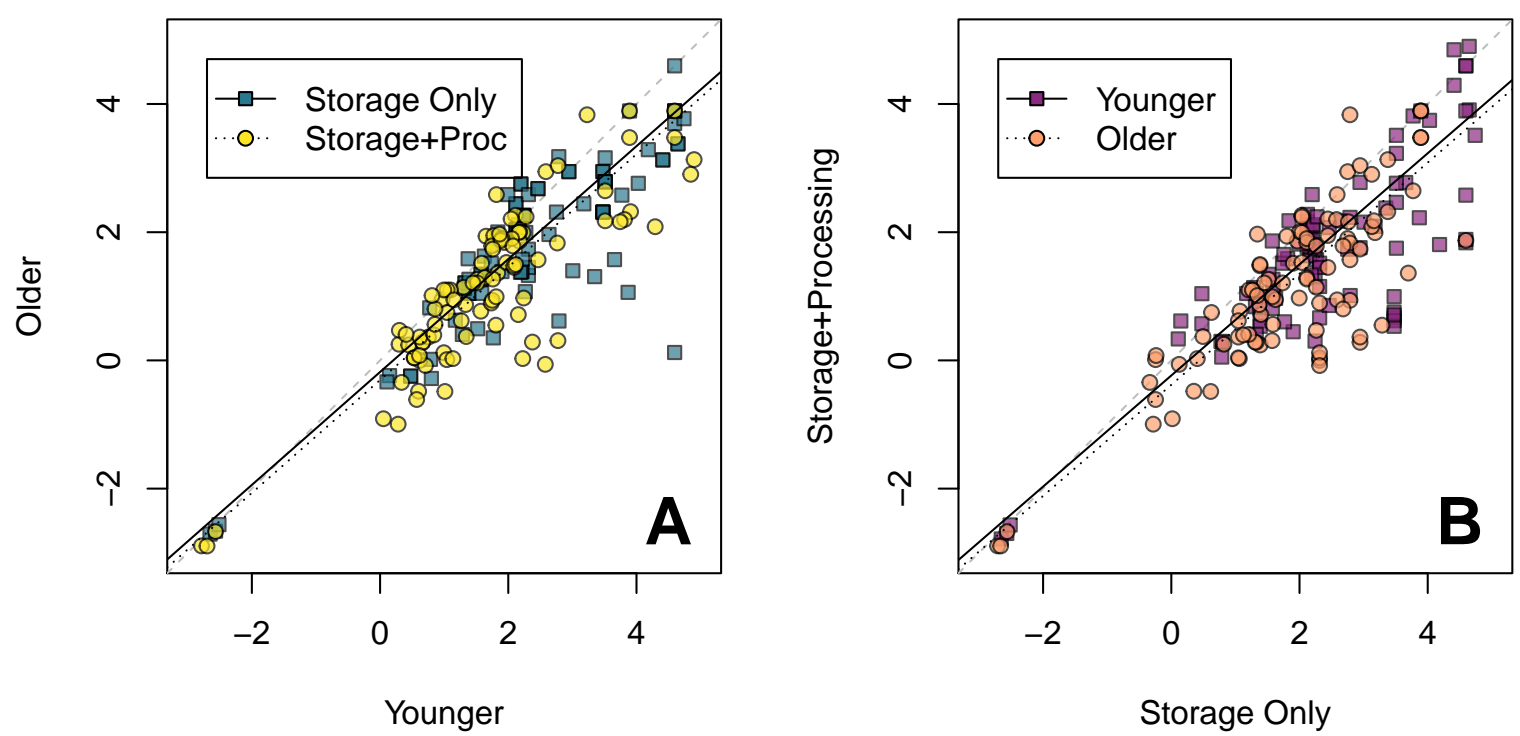

Figure 2. Logit transformed accuracy presented as (A) a Brinley plot, with older adults' performance as a function of younger adults' performance for each observation in the metaanalysis, and as (B) a state-trace plot, with dual task accuracy as a function of single task. Lines are mean regression lines from the best fitting models (see text for details). 
Table 4

Results of Brinley analyses for accuracy.

\begin{tabular}{llll}
\hline & \multicolumn{1}{c}{ Model 1 } & \multicolumn{1}{c}{ Model 2 } & \multicolumn{1}{c}{ Model 3 } \\
\hline Intercept & $-0.328[-0.534,-0.117]$ & $-0.243[-0.447,-0.024]$ & $-0.233[-0.428,-0.016]$ \\
Slope & $0.936[0.831,1.048]$ & $0.881[0.778,0.986]$ & $0.876[0.771,0.979]$ \\
Task & - & $0.062[0.032,0.092]$ & $0.062[0.032,0.092]$ \\
Slope:Task & - & - & $0.004[-0.011,0.018]$ \\
WAIC & 27750 & 22745 & 24736 \\
\hline
\end{tabular}

Note. Presents mean and $95 \%$ credible interval for population coefficients. Task was coded such that storage only $=1$ and storage + processing $=-1$

single intercept and slope for both tasks; Model 2 introduces different intercepts for each task; Model 3 builds on the second by allowing for different slopes for each task. Posterior summaries for the population level coefficients for each of these models are presented in Table 4. Comparing these three models via the widely applicable information criterion (WAIC; Watanabe, 2013) favored Model 2 over Model $1\left(\Delta \mathrm{WAIC}_{1-2}=5,004.86, \mathrm{SE}=\right.$ $3,418.21)$ and Model $3\left(\Delta \mathrm{WAIC}_{2-3}=-1,990.87, \mathrm{SE}=1,249.22\right.$, although WAIC differences smaller than 1 SE may be considered indeterminate. See Vehtari, Gelman, and Gabry (2017) for discussion of model comparison with WAIC). In addition, the results for Models 2 and 3 contain coefficients that differ from zero for the factor of task. Using the estimate from Model 2, the difference between the two intercepts is 0.125 [0.063, 0.184], indicating that there are two distinct Brinley functions differing in intercept for measures of storage only and storage+processing. As shown in Figure 2A, this intercept difference is quite small, consistent with the results of the above meta-analyses.

Next, given the influence of titration in our previous analysis, we added a separate intercept term for studies that did/did not titrate. We also included the interaction between titration and the effect of task on the Brinley intercept to examine whether this factor modulates the difference found above. For this model the mean intercept was $-0.216[-0.398$, -0.021] and mean slope was 0.89 [0.794, 0.995]. The effect of task on the Brinley intercept was similar to the models above and greater than zero, 0.061 [0.03, 0.091]. Titration had a clear effect on the Brinley intercept, -0.242 [-0.384, -0.092], where titrated studies yielded a higher intercept (effects coded: titration $=-1$, no titration $=1$ ). However, it did not appear to strongly modulate the effect of task on the Brinley intercept, 0.012 [-0.017, 0.041].

State-trace. In the main state-trace analysis three models were considered. In Model 1 both younger and older participants shared the same population level function relating storage only with storage+processing accuracy. In Model 2, the two groups were allowed to differ in intercept and Model 3 also allowed separate slopes for the two groups. The resulting population level coefficients are presented in Table 5. WAIC favors Model 1 over Models $2\left(\Delta \mathrm{WAIC}_{1-2}=-10,555.71, \mathrm{SE}=4,834.33\right)$ and $3\left(\Delta \mathrm{WAIC}_{1-3}=-26,765.63\right.$, $\mathrm{SE}=8,216.79)$, and Model 2 was favored over $3\left(\Delta \mathrm{WAIC}_{2-3}=-16,209.92, \mathrm{SE}=3,871.74\right)$. We note that the preference for the simple model over Model 2 is not overwhelming (the difference in WAIC amounts to approximately 2 SEs). In Model 2 the difference between the two intercepts is $0.145[0.085,0.208]$ and suggests that, for the older group, the function relating the two tasks is lower than what we would expect given the function for younger 
Table 5

Results of state-trace analyses of accuracy.

\begin{tabular}{llll}
\hline & \multicolumn{1}{c}{ Model 1 } & \multicolumn{1}{c}{ Model 2 } & \multicolumn{1}{c}{ Model 3 } \\
\hline Intercept & $-0.448[-0.756,-0.128]$ & $-0.308[-0.619,0.01]$ & $-0.281[-0.6,0.072]$ \\
Slope & $0.95[0.793,1.108]$ & $0.867[0.71,1.021]$ & $0.856[0.688,1.019]$ \\
Group & - & $0.073[0.042,0.104]$ & $0.07[0.039,0.1]$ \\
Slope:Group & - & - & $0.011[-0.004,0.025]$ \\
WAIC & 83329 & 93885 & 110094 \\
\hline
\end{tabular}

Note. Presents mean and 95\% credible interval for population level coefficients.

Group was coded such that younger $=1$ and older $=-1$

adults (see Figure 2B).

To probe this further we considered an extension to Model 2 which introduced the effect of titration, and its modulation of the group difference in state-trace intercept. For this model the mean intercept was $-0.324[-0.702,0.067]$ and slope was $0.88[0.696,1.061]$. The effect of group on the intercept was comparable to the models above, $0.074[0.043$, 0.106]. Titration did not have a clear effect on the state-trace intercept, -0.055 [-0.275, 0.161], although it did have a small effect on the group intercept term, $0.03[0,0.06]$, where not titrating tended to exacerbate group differences.

\section{Age-Related Differences in Reaction Time}

Our assessment of reaction time was limited by the fact that we could not find estimates of variability (e.g., SD) for the majority of observations $(12 / 18)$. Thus we report mean reaction times across all of the studies reporting RT weighted by sample size. In addition, we report meta-analyses of effect sizes for the three studies that reported variability (4 unique single task and 6 dual task observations: Clapp, Rubens, Sabharwal, and Gazzaley (2011); Clapp and Gazzaley (2012); Holtzer et al. (2004)).

The weighted mean reaction time in seconds for younger adults for storage only is 0.84 and for storage plus processing is 0.90 . For older adults these values were 1.14 and 1.33 , respectively. The difference in mean $\mathrm{RT}$ between storage only and storage+processing is -0.06 for the younger group and -0.18 for the older group.

For the studies reporting variability, the estimated standardized age difference was $-1.144[-2.043,-0.245](z=-2.495, p<0.05)(Q(3)=12.778, p<0.01)$ for storage only tasks and $-1.442[-2.395,-0.489](z=-2.966, p<0.01)(Q(5)=16.028, p<0.01$ for storage + processing tasks. Considering the cost to storage with processing relative to storage only revealed an age difference of $0.298[-0.01,0.607](z=1.899, p=0.058)$, which is consistent with older adults showing a greater latency difference between the two tasks, although this is not quite significantly different from zero (this was the case for the other assumed correlations: 0.271 [-0.002, 0.543] $(z=1.949, p=0.051)$ for $r=.3$ to 0.343 [-0.04, $0.726](z=1.753, p=0.08)$ for $r=.9)$. The test of residual heterogeneity was not significant when using a correlation of .3 $(Q(5)=3.561, p=0.614), .5(Q(5)=4.903, p=0.428)$, or .7 $(Q(5)=7.868, p=0.164)$ but was for $0.9(Q(5)=20.023, p<0.01)$. As noted above, we place greater weight on the results with the lower assumed correlations. 


\section{Reaction time in seconds}
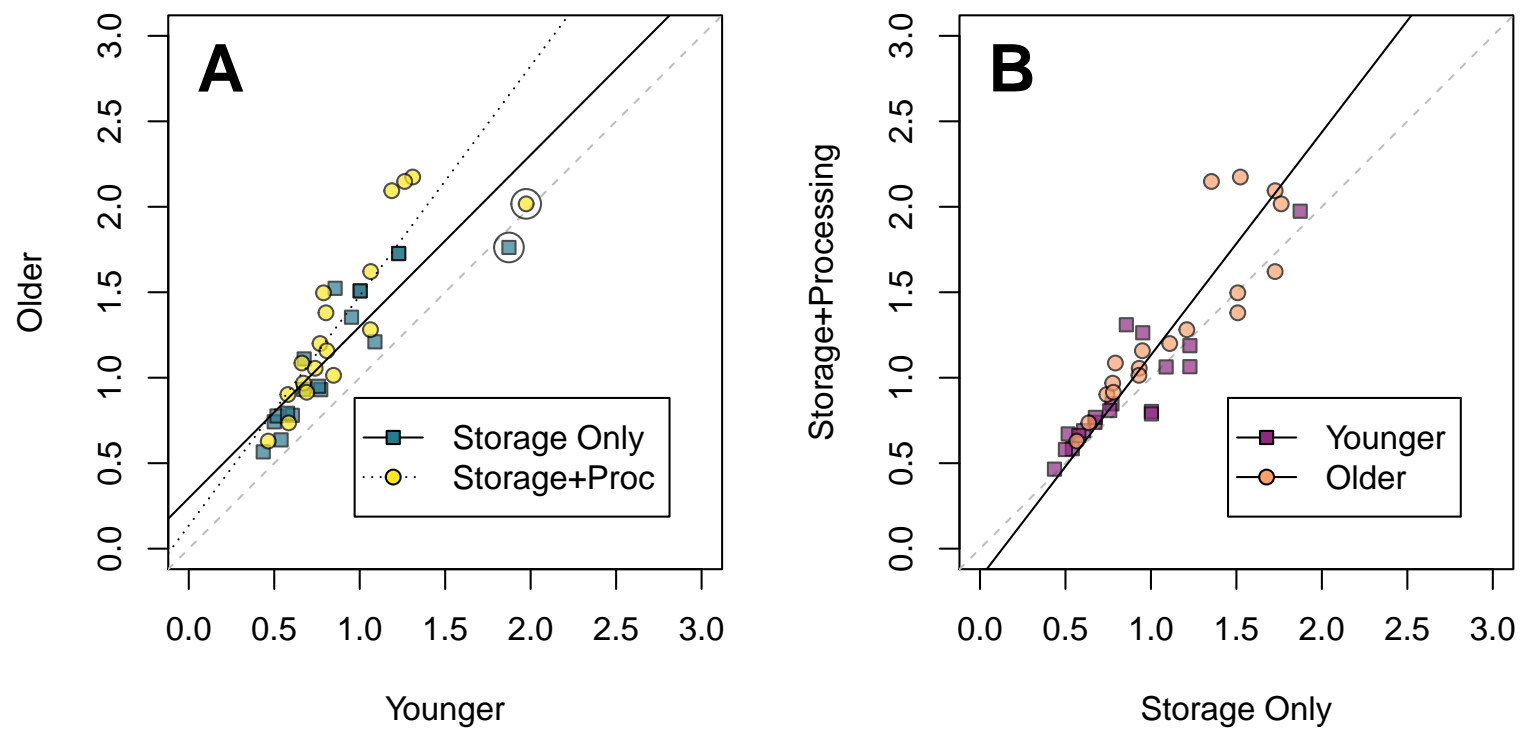

Figure 3. Reaction time presented as (A) a Brinley plot, with older adult performance as a function of younger adult performance for each observation in the meta-analysis, and as (B) a state trace plot, with dual task accuracy as a function of single task. Lines are regression lines from the best fitting models and the circled points were omitted from analysis (see text for details).

Given the small number of observations, we did not further consider moderators. However, weighted means by moderator categories, where possible, are presented in the supplement. Note that, in any case, we would not be able to include titration as a moderator in the RT analysis because speeded tasks cannot be easily titrated and we are unaware of any attempts at manipulating the number of to-be-processed items to ensure that both younger and older adults respond with comparable speed across different experimental conditions. Indeed, none of the studies reporting reaction time used titration procedures.

\section{Brinley and State-Trace Plots of Reaction Time}

Figure 3 presents the Brinley and state-trace plots for the reaction time data set. The same three general models described above were considered for reaction time. However, due to the lack of estimates of variability for the majority of observations, we used the more conventional analysis approach of fitting a weighted linear mixed effects model using the lme4 package (Bates, Mächler, Bolker, \& Walker, 2015).

Brinley. For the Brinley analysis, observations from E. E. Smith et al. (2001) were identified as influential in an ordinary least squares analysis and we excluded (circled in Figure 3A. Cook's distance of 2.85 and 1.11, respectively. Next largest $=0.11$ ). Parameter estimates and 95\% confidence intervals are presented in Table 6 along with the Akaike Information Criterion (AIC: Akaike, 1974). Following the rules of thumb outlined by Burnham and Anderson (2004), we can assess the AIC differences from the "best" model (in this case, Model 3$)$. The difference in fit between model 3 and model $1\left(\Delta \mathrm{AIC}_{3-1}=-1.05\right)$ 
and between Model 3 and Model $2\left(\Delta \mathrm{AIC}_{3-2}=-0.02\right)$ was not large enough to rule out either model (an absolute value of 10 would amount to no support relative to the winning model; values greater then 4 can be considered considerably less support, Burnham \& Anderson, 2004). Thus, while Figure 3A presents the mean regression lines for Model 3, the evidence in favor of this model is very weak. These issues notwithstanding, the parameter values for Model 3 in Table 6 suggest that older adults are disproportionately slowed for storage+processing tasks that take younger adults longer to complete. On the other hand, the coefficients for Model 2 suggest a constant slowing for older adults under dual task conditions.

Table 6

Results of Brinley analyses for reaction time.

\begin{tabular}{llll}
\hline & \multicolumn{1}{c}{ Model 1 } & \multicolumn{1}{c}{ Model 2 } & \multicolumn{1}{c}{ Model 3 } \\
\hline Intercept & $0.14[-0.153,0.433]$ & $0.25[0.009,0.491]$ & $0.216[0.007,0.425]$ \\
Slope & $1.284[0.885,1.683]$ & $1.13[0.79,1.47]$ & $1.174[0.926,1.422]$ \\
Task & - & $-0.058[-0.092,-0.024]$ & $0.08[-0.029,0.189]$ \\
Slope:Task & - & - & $-0.17[-0.298,-0.042]$ \\
AIC & -19.368 & -20.399 & -20.416 \\
\hline
\end{tabular}

Note. Presents mean and $95 \%$ confidence interval $\left(1.96^{*} \mathrm{SE}\right)$ for population coefficients. Task was coded such that storage only $=1$ and storage + processing $=-1$

State Trace. The state-trace results are presented in Table 7 . In this case Model 1 had the lowest AIC value and fit considerably better than Model $3\left(\Delta \mathrm{AIC}_{1-3}=-8.27\right)$. The difference between Models 1 and 2 was slightly less convincing $\left(\Delta \mathrm{AIC}_{1-2}=-4.90\right)$. The coefficients for Model 1 (Table 7) suggest that both younger and older adults become increasingly slower to respond to storage tasks under dual task conditions when those storage tasks require more time to complete as single tasks (see Figure 3B).

Table 7

Results of state-trace analyses of reaction time.

\begin{tabular}{llll}
\hline & \multicolumn{1}{c}{ Model 1 } & \multicolumn{1}{c}{ Model 2 } & \multicolumn{1}{c}{ Model 3 } \\
\hline Intercept & $-0.171[-0.372,0.03]$ & $-0.013[-0.263,0.237]$ & $0[-0.232,0.232]$ \\
Slope & $1.304[1.138,1.47]$ & $1.148[0.91,1.386]$ & $1.127[0.892,1.362]$ \\
Group & - & $-0.042[-0.09,0.006]$ & $0.039[-0.066,0.144]$ \\
Slope:Group & - & - & $-0.086[-0.184,0.012]$ \\
AIC & -21.767 & -16.864 & -13.492 \\
\hline
\end{tabular}

Note. Presents mean and $95 \%$ confidence interval $\left(1.96^{*} \mathrm{SE}\right)$ for population level coefficients. Group was coded such that younger $=1$ and older $=-1$

\section{Discussion}

It has been suggested that, relative to their younger counterparts, older adults' ability to retain information over short periods of time is disproportionately impaired by a concurrent processing demand (e.g., Bopp \& Verhaeghen, 2005; Broadbent \& Heron, 1962; Wingfield et 
al., 1988; Wright, 1981). Further, it has been argued that this age-related gap in performance is due to a specific deficit in coordinating the competing task requirements (Mayr \& Kliegl, 1993; Salthouse, 1990). However, in the working memory literature, there have been many contradictory reports where no differential age effect has been found for tasks requiring both storage and processing, relative to storage only (e.g., M. Anderson et al., 2011; A. D. Baddeley et al., 1986; Jenkins et al., 1999; Logie et al., 2004). Here we identified aspects of study methodology that may affect the magnitude of the reported age effects, leading either to an underestimation of older adults' ability to perform under dual task conditions in working memory paradigms, or an underestimation of the age-related deficit.

Firstly, many reports of no differential dual task cost with advancing age have preadjusted, or titrated, the level of difficulty of the individual tasks prior to their combination. Removing age differences in single task has been suggested to be key to eliminating age differences in dual task performance (cf. Somberg \& Salthouse, 1982). We return to this point below. Secondly, the nature of the stimuli used and whether there is overlap in the domain (verbal, nonverbal) between the two tasks also appears to modulate findings. Finally, beside the question of whether age differences are larger for storage+processing, there is the additional issue of whether a differential drop in performance is indicative of a disproportionate age effect, which may require a specific mechanism (e.g., coordinative deficits) to explain. The current meta-analysis aimed to address these issues.

We focused on studies that reported direct comparisons of a storage task performed in isolation with that same task performed with a concurrent processing demand. With regard to accuracy data, synthesizing the results of these studies we find evidence for a small, but significant, differential age effect on the ability to store information over brief intervals when concurrent processing is required. The results for reaction time were generally similar but we were limited by the number of studies that report latency in this literature. Further, for accuracy, this age effect appears to be disproportionate; two functions are needed to predict the performance of older adults from the performance of the younger group: one for storage alone and one for storage+processing. Note, however, that the differences between Brinley and state-trace models are relatively small (Figure 2) and the presence of this specific age difference should be explored further in future studies using methods appropriate for identifying specific cognitive processes (see Dunn \& Kirsner, 1988; Prince et al., 2012).

With respect to moderators, titration appeared to play a role in modulating the extent of the age-difference in storage+processing performance. Effect sizes were considerably smaller and not significantly different from zero for studies that adjusted task demand prior to combining storage with processing. Overlap in the domains of the storage and processing tasks (i.e., both verbal or nonverbal) had a clear effect on age differences generally. There was also some evidence that concurrence costs were larger when the two tasks overlapped in terms of the type of stimuli involved in the tasks. However, including both titration and overlap in a meta-regression pointed more strongly to a role of titration in this regard.

In line with previous research (e.g., Hale \& Myerson, 1996; Jenkins et al., 1999, 2000; Myerson et al., 1999; for an exception, see Park et al., 2002) assessing performance accuracy, we found that verbal storage+processing tasks produced smaller age effects than the corresponding tasks using visuospatial materials. This result demonstrates the oftenreplicated dissociation between verbal and nonverbal age effects: verbal processes appear to be relatively spared by aging, whereas nonverbal processes exhibit stronger age-related 
declines (e.g., Hale \& Myerson, 1996; Johnson et al., 2010; Park et al., 2002). What is less clear is how overlap in the domain of storage and processing tasks affects older adults' ability to temporarily hold information in mind. We found some evidence that overlap, particularly when both tasks used nonverbal stimuli, was detrimental to older adults' dual task performance. However, we also observed that studies with overlap tended to be those that did not adjust the level of single task demand ahead of combining the tasks. ${ }^{4}$ Once we accounted for this confounding in a meta-regression, the role of domain overlap in age differences in dual task costs was less clear (see Table 3). Thus, with regard to task domain, our results are consistent with the extant literature in supporting an overall role of domain in age differences but little role in modulating the extent of costs to concurrent storage and processing (Hale \& Myerson, 1996; Jenkins et al., 1999, 2000; Myerson et al., 1999).

As we described in the Introduction, there is a suggestion in the literature that titrating single task demand for storage and processing tasks prior to their combination eliminates age differences in dual task performance. However, to our knowledge, no one has directly compared age differences in working memory dual task costs under titrated and non-titrated conditions and there are, at present, no standardized procedures for estimating each individual's ability to perform the concurrent tasks in isolation. ${ }^{5}$ In addition, many studies in which titration has been adopted have had rather small samples (e.g., M. Anderson et al., 2011; A. D. Baddeley et al., 2001, 1986; Logie et al., 2004), which raises the obvious question of whether it is titration per se that is modulating the size of the effect, or simply the inability of designs to resolve even fairly large age differences found in other studies (e.g., Bier et al., 2017; Rhodes et al., 2019). Our approach is not quite direct, as effect sizes under investigation came from different experiments, but does serve to compare the effect sizes of studies that did and did not adopt a titration procedure. More importantly, the meta-analytic approach allowed us to combine the results of the many small studies that have used titration to better estimate effect size.

Our findings are in line with the assertions in the literature that adjusting the demand of storage and processing tasks prior to combining them reduces age differences in dual task performance to the extent that they are not significantly different from zero. However, what is missing in the literature is a detailed rationale of what titration actually achieves. Previous arguments in favor of adopting titration have been based on measurement considerations; interpretation of task-by-age-group interactions is facilitated when groups share a common baseline (Somberg \& Salthouse, 1982). In this case the interaction cannot be transformed away with a monotonic function (Loftus, 1978). Of course, measurement considerations are important but, as noted by Guttentag (1989), if titration removes, or greatly diminishes, all dual task effects (i.e., even those expected in younger adults' performance) it may be that there is an effective ceiling effect in the data for all age groups.

One theoretical rationale has been provided for titration from the multiple component

\footnotetext{
${ }^{4}$ There is an interesting possible reason for this. Titration has largely been adopted by researchers working with a multiple component conception of working memory (e.g., A. D. Baddeley et al., 2001, 1986; Logie et al., 2004). Under this framework, titration serves to ensure that individual components of the system are not overloaded (see Logie, 2011). Importantly, these researchers tend to select tasks such that they do not overlap in domain to ensure that different supposed components of working memory can be presumed to underlie performance.

${ }^{5}$ The data file containing information about the titration procedures implemented in each study included in the meta-analysis can be found on the Open Science Framework (https://osf.io/bp359/).
} 
account of working memory. The proposal is that, once individual components of working memory are overloaded, participants draw on other aspects of the system to support performance (Logie, 2011, 2016). The argument follows that, unless demand is titrated, the conflict between storage and processing may be due to exceeding the capacity of individual components of the working memory system. This leads to the expectation that storage+processing conflict will emerge only when participants are pushed beyond their titrated span level, a proposal for which there is mixed support (see Doherty \& Logie, 2016; Doherty et al., 2018; Rhodes et al., 2019). Further, the multiple component account might also predict that participants with larger spans would show smaller concurrence costs in tasks that are untitrated, as it is less likely that the task would exceed their actual ability. To our knowledge, however, concurrent task effects tend to be larger for participants with greater spans (e.g., Kane \& Engle, 2000; Rhodes et al., 2019; Rosen \& Engle, 1997). Kane and Engle (2000) and Rosen and Engle (1997) speculated that high-span young adults make greater use of attentional resources to enhance performance, which they cannot do well under dual task conditions. Moreover, in their meta-analytic investigation of $n$-back performance as a function of age and $n$, Bopp and Verhaeghen (2018) found that age effects are relatively small when going from 0 -back to 1-back, but larger when $n>1$. If the only constraint on performance is imposed by the limited-capacity of individual components of the working memory system, which titration is assumed to correct for, older adults should be able store at least 2-3 items at a time. Bopp and Verhaeghen's (2018) finding that age-related differences remained stable over values of $n$ from 2-back onwards, suggests that the constraint is not working memory load per se, but rather the involvement of focus switching processes. Thus, it appears that titration does play a role in reducing age differences, but the theoretical insight this reduction provides into the functional underpinnings of working memory remains unclear.

\section{Limitations and Prospects for Future Research}

Our meta-analysis focused on short-term storage, or memory accuracy under single and dual task conditions. We did not include performance of the concurrent processing task in our analyses for two reasons. First, researchers typically do not assess (or report) single task processing performance, which means that there is no appropriate baseline for assessing concurrence costs. Therefore, much like Verhaeghen et al. (2003), who focused on performance of the "primary task" in their meta-analysis of the wider dual task literature, we explored only one half of the data. This likely influenced our effect size estimates. Second, as can be seen in Table 1, there is considerable heterogeneity in the types of processing activities used in dual task paradigms (e.g., time spent on target, discrimination accuracy, pinch force control). This lack of consistency precludes meaningful indexing of processing performance (i.e., estimating performance on a common scale). Among the few publications that do include single and dual task measures of processing performance, there are reports of the slowing of concurrent processing along with no significant age effect on memory accuracy (Bier et al., 2017; Logie et al., 2007). In these cases the processing task did not enforce a response deadline, whereas recently we (Rhodes et al., 2019) used a task in which responses could not be slowed in this way and found a large effect of age on storage performance (see Doherty et al., 2018 for similar results in younger adults). Age-related decline in response speed is well established (e.g., Der \& Deary, 2006; Nettelbeck \& Rabbitt, 1992). Therefore, 
it seems almost certain that a sizable portion of the residual heterogeneity observed in our meta-analyses can be accounted for by whether or not the processing task adopted in each study involves a speeded response (MacPherson et al., 2007). Our analyses of the moderating role of response deadline did not reveal a significant role in influencing age differences. However, in this case we were only able to achieve a coarse categorization of deadline and the majority of studies used deadlines much longer than those of Rhodes et al. (2019). Future work should endeavor to take the nature of the processing tasks into account by directly comparing processing task requirements and assessing their potential moderating effects by measuring speed-accuracy trade-offs.

Relatedly, studies in the wider literature on aging and dual tasking using the psychological refractory period (PRP) effect have found that, while older adults still exhibit a dual task cost following substantial training (Maquestiaux, Didierjean, Ruthruff, Chauvel, \& Hartley, 2013), there are certain task responses that may remain almost entirely automatic with age. These largely involve well-learned responses such as word recognition (Lien et al., 2006) and ideomotor responses (where the sensory feedback produced by the response is related to the stimulus, Hartley, Seaman, \& Maquestiaux, 2015). It would be interesting to assess whether age-related deficits in storage combined with concurrent processing, even for un-titrated supraspan lists, can be reduced or eliminated with processing tasks that appear to remain largely automatic with age. An interesting approach, that may serve to link the storage and processing in working memory literature to the literature on PRP effects, might be to assess age differences in storage+processing as a function of the PRP effect elicited by a particular task. To the extent that the observed age effects in both literatures are related (for discussion, see Maquestiaux, 2016), this may go some way towards explaining the substantial heterogeneity in effect sizes observed here.

With regard to our analyses, as noted above, we had to assume certain correlations between single and dual task performance in order to try and meta-analyse age differences in the dual task cost. Further, in each of the analyses we made the simplifying assumption that the correlation was the same for the younger and older groups. As a consequence, we reported a range of effect sizes and associated confidence intervals (see supplement) rather than a single point estimate. However, it is not possible to rectify this limitation without access to the raw data (or single - dual task correlations) for each experiment. Current trends towards sharing raw data in cognitive psychology will improve things in this regard.

In our analyses aimed at probing the dimensions in the data we made the simplifying assumption that the relationship between the two variables (younger and older adults' performance in the case of Brinley, single and dual task performance in the case of statetrace) is linear (see also; Bopp \& Verhaeghen, 2005; Verhaeghen et al., 2003). We cannot fully rule out that some other monotonic function would suffice in explaining the data, and thus that only a single function would provide a better fit in the case of our accuracy analyses. Nevertheless, we transformed accuracy to a more appropriate scale for modeling and the figures suggest that linearity is not a gross misspecification (see Figure 2). Further, unlike previous assessments of Brinley and state-trace functions in the literature, we applied a model that is better placed to make use of the information available to meta-analysts and also acknowledges the fact that both the predictor and outcome variables are measured with error (see supplement). 


\section{Conclusion}

In sum, the present meta-analyses demonstrate a small differential effect of age on tasks requiring the temporary storage and processing of information, relative to storage alone. This age effect remains disproportionate in supplementary Brinley and state-trace analyses, further suggesting that a particular cognitive mechanism is at play. The literature strongly suggests that this mechanism would relate to the ability to successfully manage and coordinate multiple task demands (Mayr \& Kliegl, 1993; Mayr et al., 1996) and taskswitching between maintenance activities and the concurrent requirements (Verhaeghen, 2011; Wasylyshyn, Verhaeghen, \& Sliwinski, 2011).

Adjusting the level of demand of the two tasks prior to their combination appears to reduce the magnitude of age differences to near zero. What is lacking, however, is a convincing theoretical account of why this is the case, especially in light of recent strong demonstrations to the contrary (Bier et al., 2017; Rhodes et al., 2019). Finally, there remains substantial variability in effect sizes, which we argue points to the important factor of the nature of the processing task, beyond the broad type of stimuli used. Further work directly comparing different processing tasks (e.g., those with or without a speeded response deadline, or those chosen on the basis of age-differences in PRP effects) is needed to assess an important potential source of this variability. 


\section{References}

Aben, B., Stapert, S., \& Blokland, A. (2012). About the distinction between working memory and short-term memory. Frontiers in Psychology, 3, 301.

Adams, E. J., Nguyen, A. T., \& Cowan, N. (2018). Theories of working memory: Differences in definition, degree of modularity, role of attention, and purpose. Language, Speech, and Hearing Services in Schools, 49(3), 340-355.

Akaike, H. (1974). A new look at the statistical model identification. IEEE Transactions on Automatic Control, 19(6), 716-723.

Anderson, M., Bucks, R. S., Bayliss, D. M., \& Della Sala, S. (2011). Effect of age on dual-task performance in children and adults. Memory $\&$ Cognition, 39(7), 1241-1252.

Aust, F., \& Barth, M. (2018). papaja: Create APA manuscripts with $R$ Markdown. Retrieved from https://github.com/crsh/papaja

Baddeley, A. D., Baddeley, H. A., Bucks, R., \& Wilcock, G. (2001). Attentional control in alzheimer's disease. Brain, 124 (8), 1492-1508.

Baddeley, A. D., Logie, R. H., Bressi, S., Sala, S. D., \& Spinnler, H. (1986). Dementia and working memory. The Quarterly Journal of Experimental Psychology, 38(4), 603-618.

Bamber, D. (1979). State-trace analysis: A method of testing simple theories of causation. Journal of Mathematical Psychology, 19(2), 137-181.

Barrouillet, P., Bernardin, S., Portrat, S., Vergauwe, E., \& Camos, V. (2007). Time and cognitive load in working memory. Journal of Experimental Psychology: Learning, Memory, and Cognition, 33(3), 570-585.

Bates, D., Mächler, M., Bolker, B., \& Walker, S. (2015). Fitting linear mixed-effects models using lme4. Journal of Statistical Software, 67(1), 1-48. doi:10.18637/jss.v067.i01

Bayliss, D. M., Jarrold, C., Gunn, D. M., \& Baddeley, A. D. (2003). The complexities of complex span: Explaining individual differences in working memory in children and adults. Journal of Experimental Psychology: General, 132(1), 71.

Bier, B., Lecavalier, N. C., Malenfant, D., Peretz, I., \& Belleville, S. (2017). Effect of age on attentional control in dual-tasking. Experimental Aging Research, 43(2), 161-177.

Bopp, K. L., \& Verhaeghen, P. (2005). Aging and verbal memory span: A meta-analysis. The Journals of Gerontology Series B: Psychological Sciences and Social Sciences, 60(5), P223-P233.

Bopp, K. L., \& Verhaeghen, P. (2007). Age-related differences in control processes in verbal and visuospatial working memory: Storage, transformation, supervision, and coordination. The Journals of Gerontology Series B: Psychological Sciences and Social Sciences, 62(5), P239-P246.

Bopp, K. L., \& Verhaeghen, P. (2018). Aging and n-back performance: A meta-analysis. The Journals of Gerontology: Series B.

Brinley, J. F. (1965). Cognitive sets, speed and accuracy of performance in the elderly. Behavior, Aging and the Nervous System, 114-149.

Broadbent, D., \& Heron, A. (1962). Effects of a subsidiary task on performance involving immediate memory by younger and older men. British Journal of Psychology, 53(2), 189-198.

Brown, J. (1958). Some tests of the decay theory of immediate memory. Quarterly Journal 
of Experimental Psychology, 10(1), 12-21.

Burnham, K. P., \& Anderson, D. R. (2004). Multimodel inference: Understanding aic and bic in model selection. Sociological Methods 83 Research, 33(2), 261-304.

Bürkner, P.-C. (2017). brms: An R package for Bayesian multilevel models using Stan. Journal of Statistical Software, 80(1), 1-28.

Bürkner, P.-C. (2018). Advanced Bayesian Multilevel Modeling with the R Package brms. The $R$ Journal, 10(1), 395-411.

Caljouw, S. R., Veldkamp, R., \& Lamoth, C. J. (2016). Implicit and explicit learning of a sequential postural weight-shifting task in young and older adults. Frontiers in Psychology, 7 .

Carpenter, B., Gelman, A., Hoffman, M., Lee, D., Goodrich, B., Betancourt, M., .. others. (2016). Stan: A probabilistic programming language. Journal of Statistical Software, $20(2), 1-37$.

Cerella, J. (1985). Information processing rates in the elderly. Psychological Bulletin, 98(1), $67-83$.

Cerella, J. (1990). Aging and information-processing rate. In Handbook of the psychology of aging (third edition) (pp. 201-221). Elsevier.

Cerella, J., Poon, L. W., \& Williams, D. M. (1980). Age and the complexity hypothesis.

Clapp, W. C., \& Gazzaley, A. (2012). Distinct mechanisms for the impact of distraction and interruption on working memory in aging. Neurobiology of Aging, 33(1), 134-148.

Clapp, W. C., Rubens, M. T., Sabharwal, J., \& Gazzaley, A. (2011). Deficit in switching between functional brain networks underlies the impact of multitasking on working memory in older adults. Proceedings of the National Academy of Sciences, 108(17), $7212-7217$.

Cocchini, G., Logie, R. H., Della Sala, S., MacPherson, S. E., \& Baddeley, A. D. (2002). Concurrent performance of two memory tasks: Evidence for domain-specific working memory systems. Memory \& Cognition, 30(7), 1086-1095.

Conway, A. R., Kane, M. J., Bunting, M. F., Hambrick, D. Z., Wilhelm, O., \& Engle, R. W. (2005). Working memory span tasks: A methodological review and user's guide. Psychonomic Bulletin \&5 Review, 12(5), 769-786.

Cowan, N. (2017). The many faces of working memory and short-term storage. Psychonomic Bulletin \& Review, 24 (4), 1158-1170.

Craik, F. I. M. (1977). Age differences in human memory. In J. E. Birren \& K. W. Schaie (Eds.), Handbook of the psychology of aging (pp. 384-420). New York, NY: Van Nostrand Reinhold.

Craik, F. I. M., \& Byrd, M. (1982). Aging and cognitive deficits: The role of attentional resources. In F. I. M. Craik \& S. Trehub (Eds.), Aging and cognitive processes (pp. 191-211). New York: Plenum.

Dahl, D. B. (2016). Xtable: Export tables to latex or html. Retrieved from https://CRAN. R-project.org/package $=$ xtable

Daneman, M., \& Carpenter, P. A. (1980). Individual differences in working memory and reading. Journal of Verbal Learning and Verbal Behavior, 19(4), 450-466.

De Ribaupierre, A., \& Ludwig, C. (2003). Age differences and divided attention: Is there a general deficit? Experimental Aging Research, 29(1), 79-105.

Della Sala, S., Foley, J. A., Beschin, N., Allerhand, M., \& Logie, R. H. (2010). Assessing 
dual-task performance using a paper-and-pencil test: Normative data. Archives of Clinical Neuropsychology, 25(5), 410-419.

Der, G., \& Deary, I. J. (2006). Age and sex differences in reaction time in adulthood: Results from the united kingdom health and lifestyle survey. Psychology and Aging, 21(1), 62.

Dobbs, A. R., \& Rule, B. G. (1989). Adult age differences in working memory. Psychology and Aging, 4(4), 500-503.

Doherty, J. M., \& Logie, R. H. (2016). Resource-sharing in multiple-component working memory. Memory $\&$ Cognition, $44(8), 1157-1167$.

Doherty, J. M., Belletier, C., Rhodes, S., Jaroslawska, A. J., Camos, V., Barrouillet, P., ... Logie, R. H. (2018). Dual-task costs in working memory: An adversarial collaboration. Journal of Experimental Psychology: Learning, Memory, $\&$ Cognition, in press.

Doumas, M., \& Krampe, R. T. (2013). Ecological relevance determines task priority in older adults' multitasking. Journals of Gerontology Series B: Psychological Sciences and Social Sciences, $70(3), 377-385$.

Dumas, J. A., \& Hartman, M. (2008). Adult age differences in the access and deletion functions of inhibition. Aging, Neuropsychology, and Cognition, 15(3), 330-357.

Dunn, J. C., \& Kirsner, K. (1988). Discovering functionally independent mental processes: The principle of reversed association. Psychological Review, 95(1), 91.

Engle, R. W. (2002). Working memory capacity as executive attention. Current Directions in Psychological Science, 11(1), 19-23.

Engle, R. W., Tuholski, S. W., Laughlin, J. E., \& Conway, A. R. (1999). Working memory, short-term memory, and general fluid intelligence: A latent-variable approach. Journal of Experimental Psychology: General, 128(3), 309.

Farmer, E. W., Berman, J. V., \& Fletcher, Y. L. (1986). Evidence for a visuo-spatial scratch-pad in working memory. The Quarterly Journal of Experimental Psychology, $38(4), 675-688$.

Foley, J. A., Cocchini, G., Logie, R. H., \& Della Sala, S. (2015). No dual-task practice effect in alzheimer's disease. Memory, $23(4), 518-528$.

Gamble, K. R., Howard Jr, J. H., \& Howard, D. V. (2014). Does a simultaneous memory load affect older and younger adults' implicit associative learning? Aging, Neuropsychology, and Cognition, 21(1), 52-67.

Gelman, A., Carlin, J. B., Stern, H. S., Dunson, D. B., Vehtari, A., \& Rubin, D. B. (2014). Bayesian data analysis (Vol. 3). Chapman \& Hall/CRC Boca Raton, FL, USA.

Gick, M. L., Craik, F. I. M., \& Morris, R. G. (1988). Task complexity and age differences in working memory. Memory \& Cognition, 16(4), 353-361.

Göthe, K., Oberauer, K., \& Kliegl, R. (2007). Age differences in dual-task performance after practice. Psychology and Aging, 22(3), 596.

Guttentag, R. E. (1989). Age differences in dual-task performance: Procedures, assumptions, and results. Developmental Review, 9(2), 146-170.

Hale, S., \& Myerson, J. (1996). Experimental evidence for differential slowing in the lexical and nonlexical domains. Aging, Neuropsychology, and Cognition, 3(2), 154-165.

Hale, S., Rose, N. S., Myerson, J., Strube, M. J., Sommers, M., Tye-Murray, N., \& Spehar, B. (2011). The structure of working memory abilities across the adult life span. 
Psychology and Aging, 26(1), 92-110.

Hartley, A. A., Seaman, B., \& Maquestiaux, F. (2015). Ideomotor-compatible tasks partially escape dual-task interference in both young and elderly adults. Psychology and Aging, 30(1), 36.

Hasher, L., \& Zacks, R. T. (1988). Working memory, comprehension, and aging: A review and a new view. In Psychology of learning and motivation (Vol. 22, pp. 193-225). Elsevier.

Hedges, L. V. (1981). Distribution theory for glass's estimator of effect size and related estimators. Journal of Educational Statistics, 6(2), 107-128.

Holtzer, R., Stern, Y., \& Rakitin, B. C. (2004). Age-related differences in executive control of working memory. Memory \& Cognition, 32(8), 1333-1345.

Jarrold, C., \& Towse, J. N. (2006). Individual differences in working memory. Neuroscience, $139(1), 39-50$.

Jenkins, L., Myerson, J., Hale, S., \& Fry, A. F. (1999). Individual and developmental differences in working memory across the life span. Psychonomic Bulletin 8 Review, $6(1), 28-40$.

Jenkins, L., Myerson, J., Joerding, J. A., \& Hale, S. (2000). Converging evidence that visuospatial cognition is more age-sensitive than verbal cognition. Psychology and Aging, 15(1), 157.

Johnson, W., Logie, R. H., \& Brockmole, J. R. (2010). Working memory tasks differ in factor structure across age cohorts: Implications for dedifferentiation. Intelligence, 38(5), 513-528.

Kane, M. J., \& Engle, R. W. (2000). Working-memory capacity, proactive interference, and divided attention: Limits on long-term memory retrieval. Journal of Experimental Psychology: Learning, Memory, and Cognition, 26(2), 336.

Kempe, M., Kalicinski, M., \& Memmert, D. (2015). Naturalistic assessment of everyday memory performance among older adults. Experimental Aging Research, 41(4), 426-445.

Kliegl, R., Mayr, U., \& Oberauer, K. (2000). Resource limitations and process dissociations in individual differences research. In Generative mental processes and cognitive resources (pp. 337-366). Springer.

Kramer, A. F., Hahn, S., Cohen, N. J., Banich, M. T., McAuley, E., Harrison, C. R., ... others. (1999). Ageing, fitness and neurocognitive function. Nature, 400 (6743), 418.

Kray, J., \& Lindenberger, U. (2000). Adult age differences in task switching. Psychology and Aging, 15(1), 126.

Lewandowski, D., Kurowicka, D., \& Joe, H. (2009). Generating random correlation matrices based on vines and extended onion method. Journal of Multivariate Analysis, 100 (9), 1989-2001.

Li, K. Z. (1999). Selection from working memory: On the relationship between processing and storage components. Aging, Neuropsychology, and Cognition, 6(2), 99-116.

Li, S.-C., Schmiedek, F., Huxhold, O., Röcke, C., Smith, J., \& Lindenberger, U. (2008). Working memory plasticity in old age: Practice gain, transfer, and maintenance. Psychology and Aging, 23(4), 731.

Lien, M.-C., Allen, P. A., Ruthruff, E., Grabbe, J., McCann, R. S., \& Remington, R. W. (2006). Visual word recognition without central attention: Evidence for greater 
automaticity with advancing age. Psychology and Aging, 21 (3), 431.

Loftus, G. R. (1978). On interpretation of interactions. Memory $\& 3$ Cognition, 6(3), 312-319. Logie, R. H. (2003). Spatial and visual working memory: A mental workspace, 42, 37-78.

Logie, R. H. (2011). The functional organization and capacity limits of working memory. Current Directions in Psychological Science, 20(4), 240-245.

Logie, R. H. (2016). Retiring the central executive. The Quarterly Journal of Experimental Psychology, 69(10), 2093-2109.

Logie, R. H., Cocchini, G., Della Sala, S., \& Baddeley, A. D. (2004). Is there a specific executive capacity for dual task coordination? Evidence from alzheimer's disease. Neuropsychology, $18(3), 504$.

Logie, R. H., Della Sala, S., MacPherson, S. E., \& Cooper, J. (2007). Dual task demands on encoding and retrieval processes: Evidence from healthy adult ageing. Cortex, 43(1), 159-169.

Logie, R. H., Della Sala, S., Wynn, V., \& Baddeley, A. D. (2000). Visual similarity effects in immediate verbal serial recall. The Quarterly Journal of Experimental Psychology: Section A, 53(3), 626-646.

Logie, R. H., Saito, S., Morita, A., Varma, S., \& Norris, D. (2016). Recalling visual serial order for verbal sequences. Memory \& Cognition, 44(4), 590-607.

Logie, R. H., Zucco, G. M., \& Baddeley, A. D. (1990). Interference with visual short-term memory. Acta Psychologica, 75 (1), 55-74.

MacPherson, S. E., Della Sala, S., \& Logie, R. H. (2004). Dual-task interference on encoding and retrieval processes in healthy and impaired working memory. Cortex, 40(1), $183-184$.

MacPherson, S. E., Della Sala, S., Logie, R. H., \& Wilcock, G. K. (2007). Specific ad impairment in concurrent performance of two memory tasks. Cortex, 43(7), 858-865.

Maquestiaux, F. (2016). Qualitative attentional changes with age in doing two tasks at once. Psychonomic Bulletin \& Review, 23(1), 54-61.

Maquestiaux, F., Didierjean, A., Ruthruff, E., Chauvel, G., \& Hartley, A. A. (2013). Lost ability to automatize task performance in old age. Psychonomic Bulletin 6 Review, 20(6), 1206-1212.

Mayr, U., \& Kliegl, R. (1993). Sequential and coordinative complexity: Age-based processing limitations in figural transformations. Journal of Experimental Psychology: Learning, Memory, and Cognition, 19(6), 1297-1320.

Mayr, U., Kliegl, R., \& Krampe, R. T. (1996). Sequential and coordinative processing dynamics in figural transformations across the life span. Cognition, 59(1), 61-90.

McCabe, J., \& Hartman, M. (2003). Examining the locus of age effects on complex span tasks. Psychology and Aging, 18(3), 562.

Meiser, T., \& Klauer, K. C. (1999). Working memory and changing-state hypothesis. Journal of Experimental Psychology: Learning, Memory, and Cognition, 25(5), 1272.

Morey, C. C., \& Bieler, M. (2013). Visual short-term memory always requires general attention. Psychonomic Bulletin and Review, 20, 163-170.

Morey, C. C., Morey, R. D., Reijden, M. van der, \& Holweg, M. (2013). Asymmetric crossdomain interference between two working memory tasks: Implications for models of working memory. Journal of Memory and Language, 69(3), 324-348.

Morris, R. G., Craik, F. I. M., \& Gick, M. L. (1990). Age differences in working memory 
tasks: The role of secondary memory and the central executive system. The Quarterly Journal of Experimental Psychology, 42(1), 67-86.

Myerson, J., \& Hale, S. (1993). General slowing and age invariance in cognitive processing: The other side of the coin.

Myerson, J., Hale, S., Rhee, S. H., \& Jenkins, L. (1999). Selective interference with verbal and spatial working memory in young and older adults. The Journals of Gerontology Series B: Psychological Sciences and Social Sciences, 54(3), P161-P164.

Nettelbeck, T., \& Rabbitt, P. M. (1992). Aging, cognitive performance, and mental speed. Intelligence, 16(2), 189-205.

Park, D. C., Lautenschlager, G., Hedden, T., Davidson, N. S., Smith, A. D., \& Smith, P. K. (2002). Models of visuospatial and verbal memory across the adult life span. Psychology and Aging, 17(2), 299.

Parkinson, S. R., Lindholm, J. M., \& Urell, T. (1980). Aging, dichotic memory and digit span. Journal of Gerontology, 35(1), 87-95.

Peterson, D. J., \& Naveh-Benjamin, M. (2016). The role of aging in intra-item and itemcontext binding processes in visual working memory. Journal of Experimental Psychology: Learning, Memory, and Cognition, 42(11), 1713.

Peterson, L., \& Peterson, M. J. (1959). Short-term retention of individual verbal items. Journal of Experimental Psychology, 58(3), 193-198.

Prince, M., Brown, S., \& Heathcote, A. (2012). The design and analysis of state-trace experiments. Psychological Methods, 17(1), 78.

R Core Team. (2018). R: A language and environment for statistical computing. Vienna, Austria: R Foundation for Statistical Computing. Retrieved from https://www. R-project.org/

Ratcliff, R., Spieler, D., \& Mckoon, G. (2000). Explicitly modeling the effects of aging on response time. Psychonomic Bulletin \& Review, 7(1), 1-25.

Ratcliff, R., Spieler, D., \& Mckoon, G. (2004). Analysis of group differences in processing speed: Where are the models of processing? Psychonomic Bulletin $\&$ Review, 11(4), $755-769$.

Rekkas, V. P. (2006). Interference resolution in the elderly: Evidence suggestive of differences in strategy on measures of prepotent inhibition and dual task processing. Aging, Neuropsychology, and Cognition, 13(3-4), 341-365.

Rhodes, S., Jaroslawska, A. J., Doherty, J. M., Belletier, C., Naveh-Benjamin, M., Cowan, N., ... Logie, R. H. (2019). Storage and processing in working memory: Assessing dual task performance and task prioritization across the adult lifespan. Journal of Experimental Psychology: General, in press.

Riby, L., Perfect, T. J., \& Stollery, B. (2004). The effects of age and task domain on dual task performance: A meta-analysis. European Journal of Cognitive Psychology, 16(6), 863-891.

Robertson, S., Myerson, J., \& Hale, S. (2006). Are there age differences in intraindividual variability in working memory performance? The Journals of Gerontology Series B: Psychological Sciences and Social Sciences, 61(1), P18-P24.

Rose, N. S., Myerson, J., Sommers, M. S., \& Hale, S. (2009). Are there age differences in the executive component of working memory? Evidence from domain-general 
interference effects. Aging, Neuropsychology, and Cognition, 16(6), 633-653.

Rosen, V. M., \& Engle, R. W. (1997). The role of working memory capacity in retrieval. Journal of Experimental Psychology: General, 126(3), 211.

Salthouse, T. A. (1990). Working memory as a processing resource in cognitive aging. Developmental Review, 10(1), 101-124.

Salthouse, T. A. (1996). The processing-speed theory of adult age differences in cognition. Psychological Review, 103(3), 403-428.

Salthouse, T. A. (2000). Methodological assumptions in cognitive aging research. In F. I. M. Craik \& T. A. Salthouse (Eds.), The handbook of cognitive aging (2nd ed., pp. 467-498). Mahwah, NJ: Erlbaum.

Salthouse, T. A., Fristoe, N. M., Lineweaver, T. T., \& Coon, V. E. (1995). Aging of attention: Does the ability to divide decline? Memory \& Cognition, 23(1), 59-71.

Salthouse, T. A., Rogan, J. D., \& Prill, K. A. (1984). Division of attention: Age differences on a visually presented memory task. Memory \& Cognition, 12(6), 613-620.

Schroeder, P. J. (2014). The effects of age on processing and storage in working memory span tasks and reading comprehension. Experimental Aging Research, 40 (3), 308-331.

Sebastian, M. V., Menor, J., \& Elosua, M. R. (2006). Attentional dysfunction of the central executive in ad: Evidence from dual task and perseveration errors. Cortex, 42(7), 1015-1020.

Shah, P., \& Miyake, A. (1996). The separability of working memory resources for spatial thinking and language processing: An individual differences approach. Journal of Experimental Psychology: General, 125(1), 4.

Sliwinski, M. J., \& Hall, C. B. (1998). Constraints on general slowing: A meta-analysis using hierarchical linear models with random coefficients. Psychology and Aging, $13(1), 164$.

Smith, E. E., Geva, A., Jonides, J., Miller, A., Reuter-Lorenz, P., \& Koeppe, R. A. (2001). The neural basis of task-switching in working memory: Effects of performance and aging. Proceedings of the National Academy of Sciences, 98(4), 2095-2100.

Somberg, B. L., \& Salthouse, T. A. (1982). Divided attention abilities in young and old adults. Journal of Experimental Psychology: Human Perception and Performance, $8(5), 651$.

Thalmann, M., \& Oberauer, K. (2017). Domain-specific interference between storage and processing in complex span is driven by cognitive and motor operations. The Quarterly Journal of Experimental Psychology, 70(1), 109-126.

Tsang, P. S. (2013). Ageing and attentional control. The Quarterly Journal of Experimental Psychology, 66 (8), 1517-1547.

Tsang, P. S., \& Shaner, T. L. (1998). Age, attention, expertise, and time-sharing performance. Psychology and Aging, 13(2), 323.

Vaportzis, E., Georgiou-Karistianis, N., \& Stout, J. C. (2013). Dual task performance in normal aging: A comparison of choice reaction time tasks. PLOS One, 8(3), e60265.

Vecchi, T., \& Cornoldi, C. (1999). Passive storage and active manipulation in visuo-spatial working memory: Further evidence from the study of age differences. European Journal of Cognitive Psychology, 11(3), 391-406.

Vehtari, A., Gelman, A., \& Gabry, J. (2017). Practical bayesian model evaluation using 
leave-one-out cross-validation and waic. Statistics and Computing, 27(5), 1413-1432. Verhaeghen, P. (2011). Aging and executive control: Reports of a demise greatly exaggerated. Current Directions in Psychological Science, 20(3), 174-180.

Verhaeghen, P. (2013). The elements of cognitive aging: Meta-analyses of age-related differences in processing speed and their consequences. Oxford University Press.

Verhaeghen, P., \& Basak, C. (2005). Ageing and switching of the focus of attention in working memory: Results from a modified n-back task. The Quarterly Journal of Experimental Psychology Section A, 58(1), 134-154.

Verhaeghen, P., \& Hoyer, W. J. (2007). Aging, focus switching, and task switching in a continuous calculation task: Evidence toward a new working memory control process. Aging, Neuropsychology, and Cognition, 14(1), 22-39.

Verhaeghen, P., Cerella, J., Bopp, K. L., \& Basak, C. (2005). Aging and varieties of cognitive control: A review of meta-analyses on resistance to interference, coordination, and task switching, and an experimental exploration of age-sensitivity in the newly identified process of focus switching.

Verhaeghen, P., Kliegl, R., \& Mayr, U. (1997). Sequential and coordinative complexity in time-accuracy functions for mental arithmetic. Psychology and Aging, 12(4), 555.

Verhaeghen, P., Steitz, D. W., Sliwinski, M. J., \& Cerella, J. (2003). Aging and dual-task performance: A meta-analysis. Psychology and Aging, 18(3), 443-460.

Viechtbauer, W. (2010). Conducting meta-analyses in R with the metafor package. Journal of Statistical Software, 36(3), 1-48. Retrieved from http://www.jstatsoft.org/v36/i03/

Voelcker-Rehage, C., \& Alberts, J. L. (2007). Effect of motor practice on dual-task performance in older adults. The Journals of Gerontology Series B: Psychological Sciences and Social Sciences, 62(3), P141-P148.

Voelcker-Rehage, C., Stronge, A. J., \& Alberts, J. L. (2006). Age-related differences in working memory and force control under dual-task conditions. Aging, Neuropsychology, and Cognition, 13(3-4), 366-384.

Wasylyshyn, C., Verhaeghen, P., \& Sliwinski, M. J. (2011). Aging and task switching: A meta-analysis. Psychology and Aging, 26(1), 15-20.

Watanabe, S. (2013). A widely applicable bayesian information criterion. Journal of Machine Learning Research, 14(Mar), 867-897.

Whiting, W. L. (2003). Adult age differences in divided attention: Effects of elaboration during memory encoding. Aging, Neuropsychology, and Cognition, 10(2), 141-157.

Wickham, H., \& Henry, L. (2018). Tidyr: Easily tidy data with 'spread()' and 'gather()' functions. Retrieved from https://CRAN.R-project.org/package=tidyr

Wingfield, A., Stine, E. A., Lahar, C. J., \& Aberdeen, J. S. (1988). Does the capacity of working memory change with age? Experimental Aging Research, 14 (2), 103-107.

Wright, R. E. (1981). Aging, divided attention, and processing capacity. Journal of Gerontology, 36(5), 605-614.

Zeintl, M., \& Kliegel, M. (2010). Proactive and coactive interference in age-related performance in a recognition-based operation span task. Gerontology, 56(4), 421-429. 